\title{
The Physiological Foundations of the Wealth of Nations*
}

\author{
Carl-Johan Dalgaard ${ }^{\dagger}$ and Holger Strulik**
}

This Version: October 2011.

Leibniz Universität Hannover, Discussion Paper No. 480

ISSN 0949-9962

\begin{abstract}
In the present paper we advance a theory of pre-industrial growth where body size and population size are endogenously determined. Despite the fact that parents invest in both child quantity and productivity enhancing child quality, a take-off does not occur due to a key "physiological check": if human body size rises, subsistence requirements will increase. This mechanism turns out to be instrumental in explaining why income stagnates near an endogenously determined subsistence boundary. Key predictions of the model are supported by cross-country data.

Keywords: Malthusian stagnation, Subsistence, Nutrition, Body size, Population growth.

JEL: O11, I12, J13.
\end{abstract}

\footnotetext{
"We would like to thank Jeanet Bentzen, Oded Galor, Mark Gradstein, Nicolai Kaarsen, John Komlos, Omer Moav, Fidel Perez-Sebastian, Karl-Gunnar Persson and seminar participants at the 2010 AEA meeting and at Brown, Ben-Gurion, Copenhagen, Cypress, Vienna, Hannover, Fribourg, and Utrecht Universities for helpful comments. We also thank Joerg Baten and Nicola Koepke for sharing their data.

${ }^{\dagger}$ Department of Economics, University of Copenhagen, Oester Farimagsgade 5, building 26, DK-1353 Copenhagen, Denmark; email: carl.johan.dalgaard@econ.ku.dk.

${ }^{* *}$ University of Hannover, Wirtschaftswissenschaftliche Fakultät, Königsworther Platz 1, 30167 Hannover, Germany; email: strulik@vwl.uni-hannover.de.
} 


\section{INTRODUCTION}

It is increasingly recognized that the dynamic forces which shaped the "Malthusian epoch" are key factors in explaining the transition to sustained growth and thus in explaining contemporary income differences. Still, important aspects of the pre-industrial growth record remain ill understood. In particular, existing theories ignore the dynamics of human body size and its links to population dynamics and average living standards. This state of affairs is problematic in two related respects.

First, ignoring body size prevents a full understanding of the forces that engendered stagnating income per capita levels during most of human history. Evidence surveyed below strongly suggests that societies throughout history faced a fundamental body size - population size trade-off; a trade-off involving how many children to bear, and how well to feed each of them. This evidence indicates that episodes of rising income should have instigated intensified investments in offspring body size (in addition to child quantity). But in this case the standard Malthusian positive check may not suffice to bring the growth process to a halt as the tendency for diminishing returns to labor input would be counterbalanced by body-size-induced productivity gains. ${ }^{1}$ If so, what (other) mechanisms contributed to the observed long-run constancy of income per capita prior to the take-off? Why did episodes of technological change fail to generate step-wise improvements in income per capita in tandem with rising body size? By ignoring the dynamics of body size during the Malthusian epoch the existing literature cannot address these central issues.

Second, by ignoring body size the existing literature is largely silent about the determination of the level of income per capita during Malthusian times: "the level of subsistence". Biologically, subsistence requirements are inescapably linked to the size of the human body; bigger bodies are more energy requiring. Without an adequate theory of the long-run determination of human body size the notion of subsistence remain obscure, and predictions about comparative income differences across pre-industrial societies become untenable. As a consequence the existing literature cannot fully describe the economic circumstances prevailing prior to industrialization.

The present paper proposes a theory of long-run growth according to which body size as well as "subsistence requirements" are endogenously determined. Parents face a trade-off between how many children to have and how well to feed each of them. At the same time they are constrained by income and metabolic consumption requirements. A positive shock to income will induce parents to expand fertility and nutritional investments in their children. However, in the following period a "physiological check" sets in: adults of the next generation are larger and as such more energy requiring. This limits fertility and nutritional investments per child, and serves to equilibrate the economy. As a result, the economy remains in a state of stagnation even though parents invest in child quality.

The differential timing of the take-off to sustained growth has helped to shape the current global distribution of per capita income (Galor, 2006, 2010; Lucas, 2000). Yet in order to understand the timing and speed of the transition it is necessary to fully understand the country-specific economic circumstances that prevailed at the time of the take-off. The present paper proposes a theory of how key preconditions were formed and how they varied at the eve of the industrial revolution.

\footnotetext{
${ }^{1}$ See e.g., Fogel (1994, 1997), Behrmann and Rosenzweig (2004) and Weil (2007) for evidence on the positive link between body size and labor productivity.
} 
The model features overlapping generations. Individuals live for two periods; childhood and adulthood. Children are passive recipients of nutrition, determined by the parent, who is the economically active agent; we ignore matching in the marriage market and allow agents to reproduce asexually. The economic components of the model are fairly standard. A unique output good is produced using body-size-augmented labor, land, and technology; since we are focusing on pre-industrial times, technology is assumed to be parametrically fixed, and land is also a fixed factor of production. Accordingly, diminishing returns to labor input prevail. Aside from this the theory builds on three novel elements.

First, besides own consumption parents derive utility from the quantity and quality (i.e., nutrition) of their children. Both quality and quantity are normal goods. Second, the metabolic rate of the parent, our conceptualization of "subsistence", is increasing in both body size and fertility. The parent is required in each period to cover these needs. Whereas body size is predetermined at the time of optimization, fertility is a control variable. Theory and empirical evidence from biology provide this important "physiological" constraint, right down to the functional form and its parameters. The substantive implication of the constraint is that if the number of children is expanded, the parent will need to consume more for herself, leaving less resources for quality investments in the offspring. Taken together these two elements generate a natural size-number trade-off which is strongly supported by empirical evidence reviewed below. The third element is the law of motion for body size, which we derive from first principles, starting at the cellular level. The substantive implication of it is that more nutrition during childhood leads to larger adults.

These elements interact in the following way. A positive productivity shock will induce parents to have more children and invest in more nutrition per child. The better nourished children will grow up to be larger adults than their parents. However, their elevated body size implies that they will be more energy-requiring adults. This prevents them from providing the same amount of nutrition per child that their parents provided, even if their productivity and income is the same as that of their parents. Thus the increase in body size is "checked" by rising metabolic needs, a fact, which puts downward pressure on nutritional investments as well as expenditure on family size. Consequently, growth does not take hold, and the economy remains in a state of stagnation. The new steady-state is characterized by unaltered body size, constant income per capita, and higher population density.

Hence, within a country, episodes of technological change should neither lead to rising income per capita nor to greater average body size; the only lasting impact from technological advancement would be greater population density. These predictions are consistent with what appears to be known about pre-industrial development in Europe. In particular, historians have documented that average height of Europeans exhibited no significant trend over the two millennia preceding the take-off into sustained growth (Kunitz, 1987; Koepke and Baten, 2005), whereas it is well known that population density gradually rose (interrupted, chiefly, by the Plague). This does not mean, of course, that European average body size remained exactly constant. Across centuries average body size did undergo marked changes. But any gains in average stature proved to be temporary in nature; they eventually eroded away, preventing a time trend from emerging.

The model allows for an improved understanding of these dynamics; qualitatively, as explained above, but also quantitatively. To demonstrate the latter, we begin by calibrating our model such that it replicates the evolution of European population from year 0 C.E. to 1800 C.E. Subsequently we ask the model to "forecast" changes in body size over this period, which we then compare to available data. The calibrated model proves to be rather effective 
in "predicting" the evolution of body size in Europe, during the two millennia that preceded the fertility transition and take-off to growth.

While the proposed theory predicts stagnation within nations, it simultaneously suggests that the level of income per capita may differ across nations, prior to the take-off to growth. For instance, if natural selection has differentially affected body size around the world (as research in biology indicates is the case), cross-country variation in income per capita and population density should arise, according to the model. ${ }^{2}$ Conditional on technology, the model predicts that societies inhabited by larger individuals would be less populous, due to higher metabolic costs of child rearing. Moreover, societies inhabited by larger individuals should feature higher levels of income per capita, prompted by higher body-size-induced productivity and a greater land-labor ratio.

In an effort to gauge the validity of these predictions, we study a cross-section of less developed countries. The countries are all characterized by having undergone the fertility transition only very recently, or not at all. Hence, to a first approximation, our model should be a relevant description of the fertility regime within which these countries are found. Consistent with the theory, our regression analysis reveals that greater land productivity leads to greater population density, but neither to higher GDP per worker nor greater body size (measured by weight in $\mathrm{kg}$ ). At the same time, we find corroborating evidence in favor of a positive impact of body size on labor productivity. Finally, consistent with the theory, we find that societies that are inhabited by larger individuals feature lower population density, conditional on land productivity. ${ }^{3}$

Accordingly, these findings document that prior to the fertility transition and the take-off of economic growth, labor productivity is systematically higher in countries that are inhabited by individuals with greater subsistence needs. Moreover, evidence of the novel mechanism ensuring stagnation - the physiological check - is also supported by the data. In societies where individuals are larger the metabolic costs of child rearing are higher, which implies lower fertility and lower steady-state population density. With a greater land-labor ratio, and generally higher body-size-induced productivity the level of income per worker will be higher. With a higher level of income per worker larger individual body size can be sustained in the steady state.

The present paper is related to the literature on growth in the very long run, which models Malthusian stagnation and the transition to modern growth (e.g., Galor and Weil, 2000; Galor and Moav, 2002; Lucas, 2002; Hansen and Prescott, 2002; see Galor, 2006 for a survey). Particularly related is research which aims to understand the mechanics of pre-industrial development (e.g., Aiyar, Dalgaard and Moav, 2008; Ashraf and Galor, 2011; Sharp, Strulik and Weisdorf, 2012; Voigtländer and Voth, 2010). In contrast to the present paper, however, these

\footnotetext{
${ }^{2}$ While the model is not evolutionary in scope, it contains a representation of deep physiological parameters, which may have been modified by natural selection. Our model therefore allows us to asses the consequence of selection for other macro variables of interest; income per capita and population density.

${ }^{3}$ Interestingly, the detected cross-country trade-off between body size and population density, which our model predicts, is also found in virtually any other mammalian species: The inverse correlation is so pervasive that it has been labeled Damuth's law (Damuth, 1981; 1993). Moreover, a negative correlation between body size and density has been discovered for samples of contemporary hunter gatherers (Walker and Hamilton, 2008).
} 
studies ignore the evolution of body size, and assume the level of subsistence consumption is exogenously given (if introduced at all). ${ }^{4}$

The paper is also related to the anthropometric history literature, where height and fertility has been discussed in a unifying way. Weir (1993), in particular, provides a perspective on the quality-quantity trade-off that is similar to ours, and uses it to conceptually motivate an empirical analysis of the impact from the French fertility transition on height developments. ${ }^{5}$

The paper proceeds as follows. In Section 2 we survey evidence on the quantity-quality trade-off between fertility and body size. Section 3 develops the model. Section 4 proves existence, stability, and proceeds to study the steady state properties of the model along with off steady state dynamics. Section 5 confronts the model with the data, and Section 6 concludes.

\section{Size versus Number of Off-Spring: A quantity-quality trade-OfF}

In this section we review evidence from biology, anthropology, and economics which strongly suggest an operative quantity-quality trade-off between body size and family size. The important implication is that families throughout history have made quality investments, in the sense of nutrition. Periods of plenty would therefore imply an expanding number and size of people, which challenges the sufficiency of Malthus' positive check in equilibrating the economy at a constant level of subsistence.

Convincing evidence in favor of a quantity-quality trade-off is found in biology. At the level of the individual mammalian species, the inverse association between body size and rate of reproduction is by now well documented (Charnov and Ernest, 2006; Walker et al., 2008). Indeed, experimental studies manipulating offspring number or environment exist, which document the trade-off (Roff, 2002).

In the context of human populations micro evidence of the size-number trade-off is also available. In subsistence societies the inverse association between family size and size of the offspring has received support by Hagen et al. (2006) who examine the trade-off in the "Shuar" society, which resides in the tropical rainforests of Ecuador. Similarly, Walker et al. (2008) demonstrate a negative link between body size and family size across a sample of 16 subsistence-based societies. ${ }^{6}$

From the perspective of the present study the evidence amassed by biologists and anthropologists is of substantive importance, since it makes plausible that the size-number trade-off is a fundamental one. The systematic link between reproduction and body size in economically primitive societies suggests that the trade-off must have been active for a very long

\footnotetext{
${ }^{4}$ A recent contribution by Abdus and Rangazas (2011) does allow subsistence consumption to be endogenously determined by body size and activity level. In contrast to the present paper, however, individuals do not take their metabolic needs into account when optimizing (and metabolism does not increase with fertility), nor does physical stature matter to productivity. Rather than focusing on the causes of stagnation, Abdus and Rangazas use their their model to show a long-run constancy of calorie consumption during roughly the last two centuries; in their model increasing demand for food as a source of utility is off set by a declining activity level at work.

${ }^{5}$ More broadly, the anthropometric literature has long observed a link between changes in body size and movements in fertility, since nutrition during childhood influences not only adult stature but may also have a direct effect on fertility. For example, the age of menarche is reached earlier within well fed populations. A careful discussion is found in Komlos (1989), analyzing the period of take-off in the Habsburg Monarchy. Extending the theory below to include some of these additional mechanisms could be a potentially interesting topic for future work.

${ }^{6}$ See Cole (2000) and Silventoinen (2003) as well.
} 
Figure 1. Body Size of UK Girls at Age 7 and the Number of Siblings

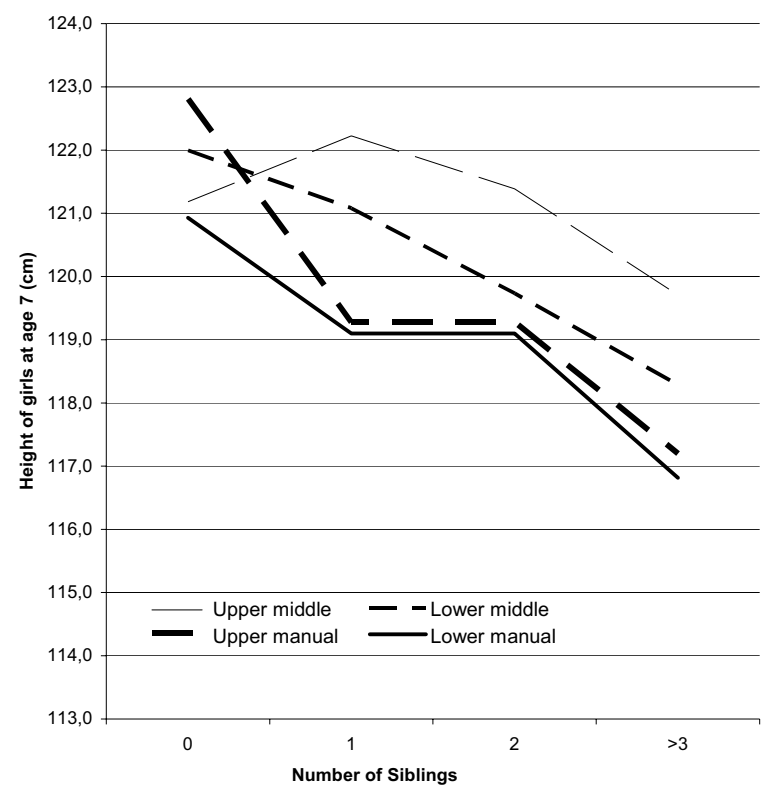

Notes. The individual lines refer to individual social classes, as defined in the text. Data source: Douglas and Simpson (1964), Table 7.

time; certainly before the take-off to sustained growth occurred in Western Europe. As a consequence, temporary income gains should be expected to translate into greater nutritional expenditure on children, implying "quality" investments. The fact that the trade-off transcends the human species implies that the mechanism responsible for it must be generic; the "physiological check", much like Malthus' positive check, fulfills this criteria.

In post-industrial societies evidence of the trade-off is found as well. In an early contribution Douglas and Simpson (1964) examined the results from a national survey of health and development in the UK. Specifically, the survey focused on 1,557 boys and 1,456 girls born in 1946. The physical development of these children was tracked and central health indicators were collected, including height, date of entry into puberty and age of menarche. In addition socio-economic indicators for the households were obtained, including occupation and educational background of the parents. This enabled Douglas and Simpson to categorize the families into social classes, ranging from "lower manual" to "upper middle". ${ }^{7}$ Figure 1 shows the association between the mean body size of girls at age of 7 and the number of siblings in the family, as reported by Douglas and Simpson.

The general pattern that emerges is one where a large family size is associated with smaller mean body size of the offspring. In addition, for the size of the family given, the average

\footnotetext{
${ }^{7}$ In the "upper middle class" we find parents with a secondary education, families where the father has a non-manual occupation, and where at least one of the parents was brought up in a middle class family with similar characteristics. In contrast, the "lower manual" group is characterized by the father being a manual laborer, by both parents only having primary education, and by upbringing; both parents were raised in a working-class family. Between these two extremes we find the "lower middle class" and "upper manual class"; these groups are differentiated from "upper middle class" and "lower manual class" mainly by their educational attainment.
} 
body size of the offspring, measured by height, generally increases as the socio-economic circumstances improve. Douglas and Simpson document that similar patterns persist to the ages of 11 and 15 for both boys and girls.

The 1946 cohort has more recently been analyzed by Kuh and Wadsworth (1989). Their regression-based analysis confirms the general impression conveyed by Figure 1; conditional on a host of environmental factors, each additional sibling implies a reduction in mean height of about $6 \mathrm{~mm}$.

At a higher level of aggregation Weir (1993) demonstrates a strong negative association between height and fertility rates across regions in France during the period 1840-1911. Following up on Weir's findings, Schneider (1996) documents similar patterns across nine European countries, covering the period 1750-1920. Controls for health and income do not overturn these findings.

In sum, the evidence discussed above pertaining to human societies as well as non-human samples quite strongly suggest an operative quantity-quality trade-off between size and number of offspring. In the next section we provide a model which encompasses this fundamental trade-off.

\section{THE MODEL}

We develop the model in a series of steps. First, Section 3.1 provides a brief introduction to the field of allometry, from which we draw an essential equation in pinning down subsistence consumption. Section 3.2 then explains how subsistence consumption is determined in the model, after which we turn to the intergenerational law of motion for body size in section 3.3. Finally, Section 3.4 and 3.5 discuss the preferences and optimization problem of parents and the production side of the economy, respectively.

3.1. An Introduction to Allometric Scaling and Energy Consumption. Allometric scaling is a technique used in biology to study how selected biological variables of an organism correlate with the size of the organism. A fundamental allometry is found between energy consumption $B$ and body mass $m$ of a mammal, and is known as "Kleiber's Law" (Kleiber, 1932):

$$
B=B_{0} \cdot m^{b}, \quad \text { with } b=3 / 4,
$$

where $B$ is the basal metabolic rate and $B_{0}$ is a species-dependent constant. Thus, drawn on log-log paper the energy-body mass relationship is linear with slope of $3 / 4$, see Figure 2 . A slope of $3 / 4$ has been verified by Brody (1945) for almost all terrestrial animals yielding the famous "mouse-to-elephant curve".

Recently biologists and physicists managed to provide a theoretical explanation for Kleiber's law. A living organism needs to feed its cells. For that purpose energy and material is transported through hierarchically branching networks like blood vessels in mammals. The network in use, however, is not of arbitrary structure. Given that organisms have evolved through natural selection, it must be one that minimizes energy used for transport i.e. one that minimizes hydrodynamic resistance. West et al. (1997) have shown that organisms, viewed as energy transporting networks that minimize energy dissipation, fulfil Kleiber's law.

The beauty of this theory lies in its foundations on first principles. This makes it very general, and in fact it has already been applied to a multitude of biological problems from "genomes to ecosystems" (West and Brown, 2005). Some of the applications and extensions, for example those on fertility, are clearly relevant for economic analysis. 
Figure 2: Kleiber's Law

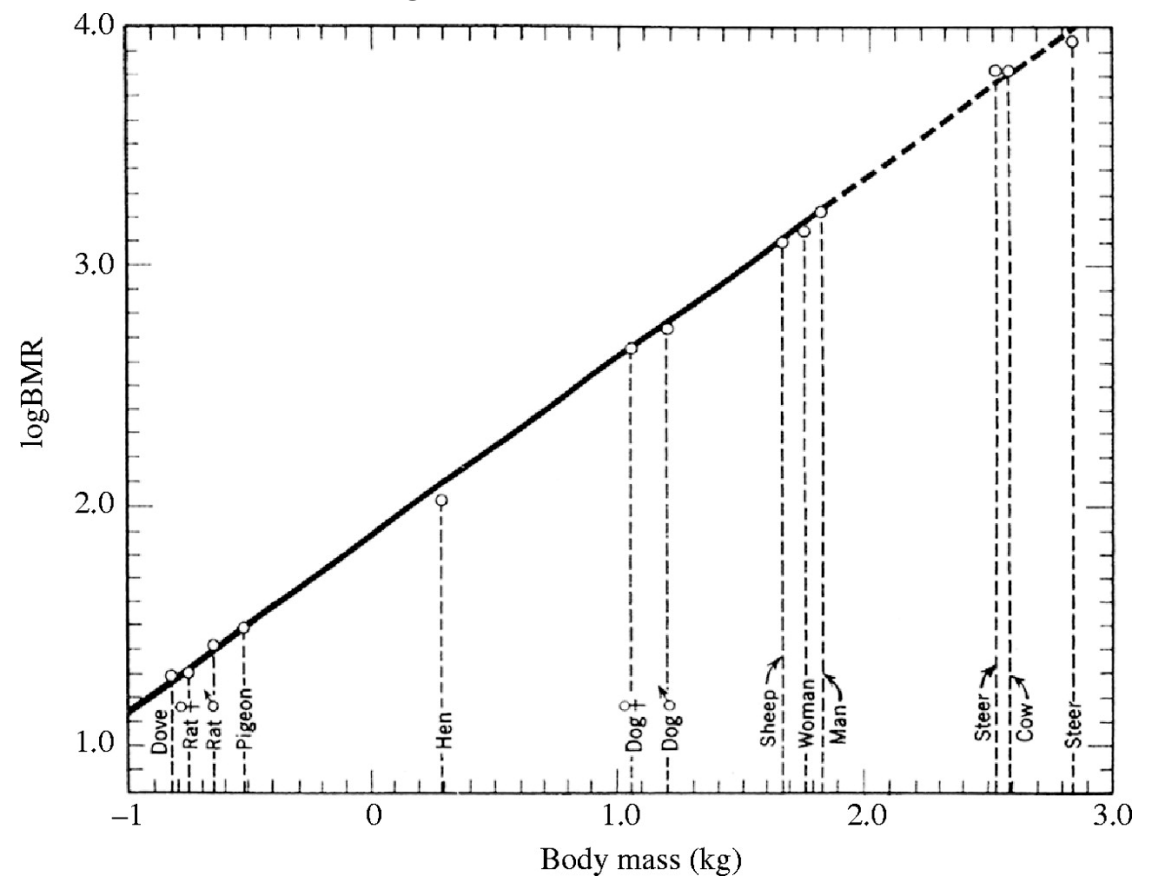

Kleiber's original Figure as reproduced in West and Brown (2005).

3.2. Subsistence Requirements. We employ Kleiber's law in order to characterize adult subsistence requirements in an overlapping generations model with endogenous fertility. According to the OLG setup life is separated into two periods. First, childhood (after weaning), defined as the period of body growth and dependence on food provided by the parent. Second, adulthood, defined as the period of constant body size, work effort and reproduction.

The body size of an adult is predetermined by the individual's nutritional intake during childhood. Accordingly, we assume that the body size of an adult remains constant. ${ }^{8}$ Subsistence consumption of an adult, however, is not completely predetermined, since it also depends on fertility. From the physiological literature we use the fact that rearing up a child from conception to weaning increases the mother's metabolic needs by a factor $\rho$ (Prentice and Whitehead, 1987; Sadurkis et al., 1988). Denoting by $B_{t}$ energy used up by the parents own body, and $n_{t}$ the number of children, total metabolic needs of an adult, $E_{t}$, is thus given by:

$$
E_{t}=\left(1+\rho \cdot n_{t}\right) \cdot B_{t}=\left(1+\rho \cdot n_{t}\right) \cdot B_{0} m_{t}^{b} .
$$

In (2) $E_{t}$ measures metabolic needs in terms of energy, expressed, for example, in kcal. per period. In order to convert energy into goods we introduce the energy exchange rate $\epsilon$, which is measured in kcal. per unit of a unique consumption good. While consumption expenditure is a control variable for parents, the energy extracted from a unit of consumption depends on the food staple available, which we treat (similar to technological progress) as exogenous.

\footnotetext{
${ }^{8}$ From now on we refer to $m_{t}$ as body size rather than body mass. This is done for semantic reasons. The term "body size" is closer to the the literature in anthropology and economic history, which focusses on human height. It also avoids confusion with the body mass index.
} 
Employing the energy exchange rate we get subsistence requirements, i.e. the metabolic needs of an adult in terms of consumption goods, $\bar{c}_{t}=E_{t} / \epsilon$. Note that, in contrast to the existing literature in economics, the subsistence requirement is not a constant but depends on the individual body size and fertility in adulthood. The variable $\bar{c}_{t}$ is therefore generationdependent and thus indexed by $t$.

3.3. The Intergenerational Law of Motion for Body Size. In order to establish the intergenerational link between body sizes we draw on West, Brown, and Enquist's (2001) model of ontogenetic growth. ${ }^{9}$ The starting point is an energy conservation equation which reads as follows:

$$
E_{t}^{c}=b_{c} N_{t}+e_{c}\left(N_{t+1}^{\prime}-N_{t}\right)
$$

where $E_{t}^{c}$ is energy consumption during childhood after weaning (prior consumption is covered by adult metabolic needs), $N_{t}$ denotes the number of human cells after weaning, $N_{t+1}^{\prime}$ is the number of cells of the child as a grown up, $b_{c}$ is the metabolic energy a cell requires during childhood for maintenance and replacement, and $e_{c}$ the energy required to create a new cell. Hence the left hand side is energy "input", and the right hand side captures energy use. Solving (3) for $N_{t+1}^{\prime}$ we obtain the number of cells of an adult as a function of the number of cells of a child after weaning and energy intake during childhood:

$$
N_{t+1}^{\prime}=\frac{E_{t}^{c}}{e_{c}}+\left(1-\frac{b_{c}}{e_{c}}\right) N_{t} .
$$

To proceed we insert the fact that body mass consists of the mass of a single cell $\bar{m}$ times the number of cells. This implies for the size of an adult that $m_{t+1}=\bar{m} N_{t+1}^{\prime}$. Moreover, using the fact that after weaning the size of a child equals $\mu$ times the size of the mother (Charnov, 1991, 1993) we have $\bar{m} N_{t}=\mu m_{t} \cdot{ }^{10}$ Substituting $N_{t}$ and $N_{t+1}^{\prime}$ in (4) and and solving for $m_{t+1}$ , gives (5):

$$
m_{t+1}=\frac{\bar{m}}{e_{c}} E_{t}^{c}+\left(1-\frac{b_{c}}{e_{c}}\right) \mu m_{t} .
$$

This intergenerational law of motion for body size has a simple interpretation: The size of the adult, $m_{t+1}$ is determined by energy consumption during childhood, $E_{t}^{c}$, plus initial size, $\mu m_{t}$, adjusted for energy needs during childhood, $-\left(b_{c} / e_{c}\right) \mu m_{t}$. Finally, denote by $c_{t}$ the consumption of a child, to be determined below from optimization. Then total energy intake during childhood is $c_{t} \cdot \epsilon=E_{t}^{c}$. Inserting this into (5) leaves us with a law of motion for body size across generations:

$$
m_{t+1}=a \cdot \epsilon \cdot c_{t}+(1-d) \cdot \mu \cdot m_{t}
$$

where $a \equiv \bar{m} / e_{c}$ and $d \equiv b_{c} / e_{c}$.

For future reference, note that $d$ and $a$ can be viewed as deep physiological parameters, which may exhibit some variation across humans due to natural selection. That is, due to processes whereby large or small bodies were selected depending on e.g. climate related circumstances.

\footnotetext{
9 "Ontogeny" describes the origin and the development of an organism from the fertilized egg to its mature form.

${ }^{10} \mathrm{~A}$ physiological justification for this assumption is that child development until weaning depends on energy consumption in utero and during the breastfeeding phase. Since larger mothers consume absolutely more energy the offspring should be larger at this point as it receives a fraction thereof. With this interpretation the linearity should be seen as a simplification. It has no substantive implications for our main results if the linearity is relaxed except for reduced tractability.
} 
3.4. Individual's Optimization. A parent maximizes utility derived from child quality and quantity where quality is in the Beckerian (1960) sense measured by expenditure for consumption (i.e. nutrition) per child, $c_{t}$. We allow the parent also to derive utility from own consumption $p_{t}$ (i.e. consumption of non-food goods) and impose for simplicity a logarithmic form for the utility function:

$$
U\left(c_{t}, n_{t}\right)=\log \left(c_{t}\right)+\beta \log \left(p_{t}\right)+\gamma \log \left(n_{t}\right), \quad \gamma>1,
$$

with $\beta$ and $\gamma$ denoting the weight of parental consumption and child quantity in utility, and $n_{t}$ the number of offspring.

Total child expenditure is constrained by parental income and subsistence consumption of the parent. Furthermore we assume that each parent is endowed with one unit of time and rearing a child requires a certain fraction $\tau$ of parental time. Let $y_{t}$ denote potential income such that available income of a family is $y_{t}\left(1-\tau \cdot n_{t}\right)$. Combining the budget constraint with energy requirements (2) and applying the energy exchange rate leads to a single constraint:

$$
y_{t}\left(1-\tau \cdot n_{t}\right)-p_{t}-c_{t} n_{t}-\left(1+\rho n_{t}\right) B_{o} m_{t}^{b} / \epsilon=0 .
$$

Observe that the model captures the full cost profile of children: the metabolic costs which are relevant until weaning $\left(\left(1+\rho n_{t}\right) B_{o} m_{t}^{b}\right)$ as well as the economic costs (time $\tau$, nutrition c) that pertain to the period after weaning. ${ }^{11}$

Parents maximize (7) s.t. (8) by choosing fertility $n_{t}$, nutritional expenditure per child $c_{t}$, and non-food consumption $p_{t}$. From the first order conditions we obtain optimal child quality and quantity,

$$
\begin{aligned}
c_{t} & =\frac{\rho\left(B_{0} / \epsilon\right) m_{t}^{b}+\tau y_{t}}{\gamma-1}, \\
n_{t} & =\frac{(\gamma-1)\left[y_{t}-\left(B_{0} / \epsilon\right) m_{t}^{b}\right]}{(\beta+\gamma)\left[\rho+\tau y_{t}\right]},
\end{aligned}
$$

together with parental consumption $p_{t}=\beta\left[y_{t}-\left(B_{0} / \epsilon\right) m_{t}^{b}\right] /(\beta+\gamma)$. Observe that $\partial n_{t} / \partial m_{t}<$ 0 and $\partial c_{t} / \partial m_{t}>0$. Greater metabolic costs of fertility induce larger parents to prefer to have less children and to nourish them better. Note furthermore that $\partial n_{t} / \partial y_{t}>0$ and $\partial c_{t} / \partial y_{t}>0$. With higher income parents prefer to have more children and to nourish them better implying that the quantity-quality trade-off is driven by metabolic needs and not by income.

It could be argued that entering child nutrition into the utility of parents is a shortcut representation of a more appropriate quality-quantity trade-off. Strictly speaking, so the argument could go, (nutritional) quality of offspring is better measured by the size of grown up children, rather than by the nutritional provisions that make the offspring grow.

Unfortunately, allowing $m_{t+1}$ to enter the utility function instead of $c_{t}$ destroys the simplicity and elegance of the baseline physiological Malthusian model. But it leads to very similar results. We provide support for this claim by developing a version of the model with "utility-from-body-size" in Appendix B; the main comparative static results derived below (Propositions 2-3) continue to hold. In Section 4 we furthermore demonstrate that the utilityfrom-body-size model displays adjustment dynamics that are very similar to those observed

\footnotetext{
${ }^{11}$ It is worth stressing that our main results go through without a temporal trade-off for parental time (i.e. for $\tau=0$ ) due to the presence of the biological trade-off originating from the fact that larger parents need more energy to sustain their own body. In spite of this we allow the time costs to appear in the interest of realism and to better relate the model to the literature on the standard quantity-quality trade-off.
} 
for the baseline model. The baseline model is thus a good approximation to the utility-frombody-size version at the steady-state and off the steady-state.

3.5. Production and Demographics. We assume that total income, $Y$, is determined at the macro-level by a body size adjusted technology:

$$
Y_{t}=A m_{t}^{\phi} L_{t}^{\alpha} X^{1-\alpha}=y_{t} \cdot L_{t}, \quad \phi>0, \alpha \in(0,1) .
$$

The parameter $\phi$ quantifies the return to body size. As usual $A$ captures technological knowledge, $L_{t}$ denotes the size of the adult population in period $t$ and $X$ is land. According to standard Malthusian theory, i.e. ignoring body size, the technology implies stagnation in the long-run unless general productivity $A$ is growing without bound since land is constant. Taking into account the physiological fact that larger bodies exert more muscles force and are thus more productive $(\phi>0)$, Malthusian stagnation follows less immediately since, in principle, living standards could improve continuously in line with increasing body size. As will be shown below, long-run stagnation in this case, requires a further condition - the physiological check - to hold.

Finally, the adult population evolves according to

$$
L_{t+1}=n_{t} L_{t}
$$

where $n_{t}$ is given by equation (9b). With equations (1) to (11) the model is complete.

\section{Steady-State, Comparative Statics and Comparative Dynamics}

4.1. Existence and Stability of the Steady-State. The model can be represented by a two-dimensional dynamic system of body size and population size. To obtain it we substitute energy consumption per child (9a) into the law of motion for body size (6) and fertility (9b) into the law of motion for population size (11). This leads to the system (12), with $y_{t}$ determined by (10).

$$
\begin{aligned}
m_{t+1} & =\frac{a \epsilon}{\gamma-1}\left[\rho\left(B_{0} / \epsilon\right) m_{t}^{b}+\tau y_{t}\right]+(1-d) \mu m_{t} \\
L_{t+1} & =\frac{(\gamma-1)\left[y_{t}-\left(B_{0} / \epsilon\right) m_{t}^{b}\right]}{(\beta+\gamma)\left[\rho\left(B_{0} / \epsilon\right) m_{t}^{b}+\tau y_{t}\right]} \cdot L_{t} .
\end{aligned}
$$

Proposition 1. Existence of a steady-state. There exists a unique steady-state $\left(m^{*}, L^{*}\right)$ $a t$

$$
\begin{aligned}
& m^{*}=\left\{\frac{a B_{0}}{(\gamma-1)[1-(1-d) \mu]}\left[\rho+\frac{\tau((\beta+\gamma) \rho+\gamma-1)}{\gamma-1-(\beta+\gamma) \tau}\right]\right\}^{1 /(1-b)} \\
& \frac{L^{*}}{X}=\left\{\frac{A \epsilon(\gamma-1-(\beta+\gamma) \tau)}{[(\beta+\gamma) \rho+\gamma-1] B_{0}}\right\}^{1 /(1-\alpha)} \cdot\left(m^{*}\right)^{\frac{\phi-b}{1-\alpha}}
\end{aligned}
$$

At the steady-state income per capita is a positive concave function of body-size:

$$
y^{*}=\frac{[(\beta+\gamma) \rho+\gamma-1] B_{0}}{[\gamma-1-(\beta+\gamma) \tau] \epsilon} \cdot\left(m^{*}\right)^{b} .
$$

Proof. At a steady-state equilibrium we observe $n^{*}=1$ and thus from (9b) we find that $Y_{t} / L_{t} \equiv y_{t}$ is given by (13c). Inserting (13c) into (12a) evaluated at $m_{t+1}=m_{t}$ provides body size at the steady-state. Using (10) and (13c) in (12b) we obtain population density at the steady-state. 
In order to assess stability and other important features of the steady-state we introduce the physiological check.

Assumption 1. The Physiological Check. The body size elasticity of metabolic needs exceeds the body-size elasticity of productivity: $b>\phi$.

Applying Kleiber's law, the physiological check requires that $\phi<3 / 4$. In the calibration below we argue in favor of a value for $\phi$ of 0.25 , implying that the physiological check is fulfilled. As will become evident below, the case where the physiological check is not fulfilled generates dynamics that are inconsistent with the pre-industrial growth record suggesting the check must have been in place throughout history. Intuitively, the physiological check requires that the elevated subsistence needs exceed the productivity gains associated with rising body size. In this regard it is interesting to observe the correspondence to Malthus' positive check, which also involves a restriction on elasticities: the population size elasticity of food demand exceeds the population size elasticity of food supply, $1>\alpha$.

In order to investigate stability we insert (10) into (12a), which provides the isocline along which body size remains constant, $\Delta m=m_{t+1}-m_{t}=0$, implicitly given by

$$
G\left(m_{t}, L_{t}\right)=[1-(1-d) \mu] \frac{\gamma-1}{a \epsilon}-\rho \frac{B_{0}}{\epsilon} m_{t}^{b-1}-\tau A m_{t}^{\phi-1} L_{t}^{\alpha-1}=0 .
$$

Implicitly differentiating we obtain $\mathrm{d} L_{t} / \mathrm{d} m_{t}<0$; the $\Delta m=0$-isocline is negatively sloped. Observe that $\Delta m<0$ when $m_{t}$ to the right of the isocline and $\Delta m>0$ when $m_{t}$ lies to the left of the isocline. Moreover, observe that $L_{t} \rightarrow 0$ for $m_{t} \rightarrow \infty$ and $L_{t} \rightarrow \infty$ for $m_{t} \rightarrow \bar{m}>0$. The resulting curve and arrows of motion are shown in the phase diagram of Figure 3.

The $\Delta L=0$-isocline in $\left(m_{t}, L_{t}\right)$-space is obtained by solving (9b) for $n=1$ and inserting the result into (12a). This provides (15).

$$
\frac{L_{t}}{X}=\left[\frac{A \epsilon(\gamma-1-\gamma \tau)}{(\gamma \rho+\gamma-1) B_{0}}\right]^{1 /(1-\alpha)} \cdot m_{t}^{\frac{\phi-b}{1-\alpha}} .
$$

Given the physiological check, $b>\phi$, the isocline is a hyperbola with $L_{t} \rightarrow 0$ for $m_{t} \rightarrow \infty$ and $L_{t} \rightarrow \infty$ for $m_{t} \rightarrow 0$. Recall that for the $\Delta m=0$-isocline $L_{t} \rightarrow \infty$ for $m_{t} \rightarrow \bar{m}>0$. Hence, there is a unique intersection between the $\Delta L=0$ and $\Delta m=0$-isoclines. Finally, observe that, when the physiological check is operative, $\Delta L_{t}<0$ above the isocline and $\Delta L_{t}>0$ below the isocline.

The arrows of motion in Figure 3 suggest that the steady-state is a globally stable spiral or node. Since time is discrete, however, a second possibility arises. There may be overshooting and explosive behavior (Galor, 2007). In Appendix A we evaluate stability numerically and show that the equilibrium is indeed stable when both the positive check $(1>\alpha)$ and the physiological check $(b>\phi)$ are operative.

We demonstrate in Appendix A that the positive check is not sufficient to generate stability. For a wide range of parameters, the economy becomes unstable if the physiological check is not operative although the positive check is operative, i.e. although $\alpha<1$. Intuitively, the $\Delta L=0$ isocline becomes positively sloped for $\phi>b$ and the arrows of motion point toward larger $L$ above the isocline. If $\phi$ becomes sufficiently large the arrows of motion for $m$ also point towards larger body sizes above the $\Delta m=0$ isocline. Taken together, this leads to a perpetual expansion path in northeastern direction. Without an operative physiological check it is thus theoretically possible that both population size and body size expand perpetually. The absence of such a trajectory in the historical record suggests that the positive check 
Figure 3: Phase Diagram

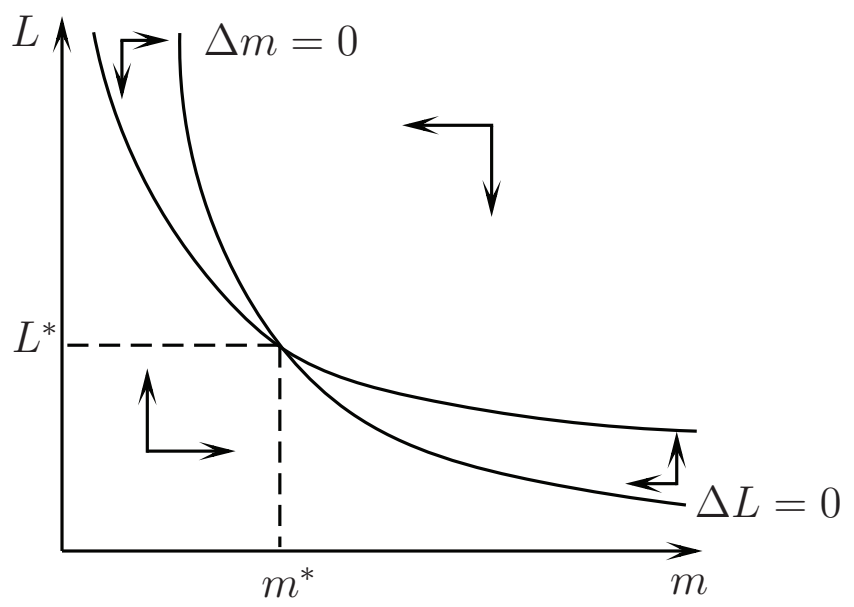

and the physiological check must have been in place. Henceforth we thus assume that the physiological check holds (as well as the positive check) and proceed to examine the steady state predictions of the model.

4.2. Comparative statics. Observe that technology $A$ enters the equation for $L^{*}$ but does not matter for $m^{*}$. In combination with (13c) this leads to the following conclusion:

Proposition 2. Technological innovations. A discrete increase in productivity (A) leads to a more densely populated area but leaves equilibrium body size and income per capita unaffected.

In the model, a temporary increase in productivity will lead to temporary increases in nutrition and fertility. However, due to the biological feed-back loop from subsistence, nutritional expenditures per child will be lower (and so will be fertility) in the following generation. This process will continue until $n=1$ once again. At this point the temporary gain in body size has fully eroded, and the only result from the innovation is a larger population size. In the long run income per capita does not change since the larger population fully offsets the increase in $A$. Note also that similar results can be derived for alternative parameter changes associated with technology improvement. Lower dependence on limited land (larger $\alpha$ ) and higher efficiency in using brawn (increasing $\phi$ ) both lead to a higher population density without an equilibrium effect on body size and - according to (13c) - on income.

There is convincing evidence testifying to the fact that technological change did increase population density in the aggregate, in pre-industrial times (e.g., Ashraf and Galor, 2011; Baker, 2008). However, the lack of a long-run time trend during the last two millennia as a whole, in terms of body size, has also been established (Kunitz, 1987; Koepke and Baten, 2005). The present theory thereby suggests that these potentially conflicting observations are in fact reconcilable.

At the same time we reiterate that these steady-state results do not preclude a positive short-run impact of productivity gains on income and body size. Comparative dynamics will be discussed below. 
Inspection of (13) proves the following.

Proposition 3. Biological innovations. In areas where humans are selected to be larger (smaller d or larger a) income per capita is larger, and population density lower.

Physical anthropologists and biologists argue that some of the observed differences in human body size, across regions and countries, may be attributed to selection (see e.g., Walker and Hamilton, 2008). In particular, one may argue that larger individuals have had a selective advantage in colder climate zones: This idea has its roots in Bergman's rule, which states that the body size of mammals tend to rise, as one moves away from the equator (e.g., Ruff, 2002).

There are two parts to the argument. First, there is the geographic observation that as one moves into colder climate zones it becomes more challenging to keep warm. Second, there is the geometric observation that as body size goes up the surface to volume ratio declines, which limits the extent of heat loss per unit of body mass. Since limited heat loss is an advantage in cooler climates, selection may have favored larger bodies in cooler areas.

If indeed such genetic differences have emerged in human societies they may be captured by $a$ and $d$ in our model. To see this observe that equation (3) does not allow for heat loss. Accordingly, the consequences of heat loss is implicit in the parameters of the energy conservation equation. Specifically, larger energy costs of running and maintaining a body cell would capture greater heat loss. In the model this is equivalent to a larger value for $b_{c}$ and thus $d$. The evolutionary argument above could thus be interpreted as saying that individuals with larger values for $d$ would have a selective advantage in areas close to the equator since it implies more heat loss, which is useful in keeping body temperature down in warm and humid environments. Observe that increasing cell costs in this way, according to the model, would produce smaller asymptotic body size. As a result, in areas where $d$ is larger (i.e., in warmer environments) individuals will be smaller and population density will be greater, ceteris paribus.

Proposition 3 implies the following corollary with testable cross-country predictions.

COROLlary 1. Suppose there are country-specific differences in the genetic determinants of body size (i.e. in parameters a and d). Then across country-specific steady-states there is (1) a negative association between population density and body size,

(2) a positive association between income per capita and body size.

Part (1) is known in the biological literature as Damuth's law (Damuth, 1981). According to our theory this empirical regularity can be ascribed to greater metabolic costs of child rearing for larger individuals, which lowers fertility and in the steady state reduces population density. Part (2) is consistent with the empirically observed positive correlation between body size and income per capita (e.g., Steckel, 1983; Brinkman et al., 1988). The corollary thus implies that body size (e.g., measured by height) is a sensible indicator of long-run income per capita, as is commonly assumed by anthropologists and economic historians. According to our model the link emerges due to greater body-size related productivity, and because population density is lower in places with larger individuals. ${ }^{12}$

\subsection{Comparative Dynamics.}

\footnotetext{
${ }^{12}$ Note that changes in $B_{0}$ would lead to the same qualitative results as those stated in the corollary. The reason why we ignore it as a plausible source of selection-based variation in body size is that $B_{0}$ in practise appears to be a constant (cf. Kleiber, 1932).
} 
4.3.1. Parameter values. In order to study the quantitative implications of the model we proceed with a calibration. We start with the biological components. We put $B_{0}=70$ and $b=0.75$ according to Kleiber's (1932) law. We set $m^{*}=54.3$ according to the average weight of females in least developed countries in our empirical sample in Section 5.

In order to get an estimate for $\rho$ we begin with observing that during pregnancy the metabolic rate rises on average by 5\%,10\% and 25\% in the first, second and third trimester, respectively (Butte and King, 2007). Pregnancy per child takes on average 3/4 of a year. In medieval Europe and China life expectancy at age 20 was around 30 years (Clark, 2007). Assuming that fecundity and thus life as a grown up starts at age 15, the length of a generation in years is given by 15 years. In medieval Europe a women gave birth to about 5 to 6 children (Clark, 2007) which implies for our unisex model that a woman gives birth to 2.5 to 3 children (of which, at the steady-state, one survives up to adulthood). This means elevated caloric needs for pregnancy per unit length of the adult period by factor $[(0.05 / 3+$ $0.1 / 3+0.25 / 3) \cdot 3 / 4 \cdot 3 / 15$. During lactation the basal metabolic rate of a woman which is exclusively breastfeeding her child rises by about 450 calories (Butte and King, 2007). Assuming a basal metabolic rate of 1500 calories for our $54.3 \mathrm{~kg}$ average mother, this implies elevated caloric needs by factor 450/1500 during the breastfeeding period. We put the age at weaning to 18 months according to the average value reported for England in the Middle Ages (Mays, 2010). Based on this observation, breastfeeding per child takes on average 1.5 years and we estimate elevated caloric needs for lactation per unit length of the adult period by factor $450 / 1500 \cdot 1.5 \cdot 3 / 15$. Taken together, we end up with an estimate for $\rho$ of $[(0.05 / 3+0.1 / 3+0.25 / 3) \cdot 3 / 4+(450 / 1500) \cdot 1.5] \cdot 3 / 15=0.11$.

To calibrate $\mu$, we observe that the weight of a 18 months old girl (i.e. at the calibrated age of weaning) is $9.4 \mathrm{~kg}$ according to World Health Organization Child Growth Standards, evaluated at the 25 th percentile. ${ }^{13}$ This implies that $\mu=9.4 / 54.3 \approx 0.173$.

For calibration of $d$, the amount of energy used for cell maintenance relative to cell creation, we turn to West et al.'s (2001) model on ontogenetic growth in continuous time, and investigate the human growth process. For the calibration we need body size at three different points in time. In addition to weight at age 18 month (end of weaning, $9.4 \mathrm{~kg}$ ) and asymptotically (mean value in our LDC sample, $54.3 \mathrm{~kg}$ ), we used the weight of a five year-old, which is 16.5 $\mathrm{kg}$ (again, at the 25th percentile). This leaves us with $d=0.37 .{ }^{14}$

To obtain $\tau$ we note that Deaton and Muellbauer (1986) estimate that in contemporaneous poor countries children cost their parents about 30-40 percent of what they spend on themselves. We thus set $\tau$ such that it implies (together with the chosen parameter values for preferences and metabolic needs) that at the steady-state children costs their parents about 40 percent of what they spend on themselves. This leads to an estimate of $\tau=0.06$.

For the economic part of the model we set $\alpha=0.65$ according to Clark's (2007) estimates. We set $\gamma=4$ in keeping an evolutionary argument behind the utility function, which is given

\footnotetext{
${ }^{13}$ This standard is documented in de Onis et al. (2007). It is worth observing that the basis for the weight-for-age curve is solely US children. Since US children may not be an accurate description of less developed economies (such as those in our sample in Section 5) we chose to use the 25th percentile, rather than the median. The choice of the 25th percentile is admittedly a somewhat arbitrary choice.In any event, the calibrated parameter values are not very sensitive to the exact choice of weight-for-age curve. For instance, $\mu$ (and $d$ below), only changes to a very minor degree if we use the 50th percentile instead.

${ }^{14}$ The continuous time ontogenetic growth equation is given by $\dot{m}=\delta m^{b}+d m$, where $d$ is the energy used for cell maintenance relative to cell creation (West et al. , 2001). From that we obtain $d=\log \left(\left[1-\left(m_{0} / m^{*}\right)^{1 / 4}\right] /\left[1-\left(m_{v} / m^{*}\right)^{1 / 4}\right]\right) \cdot 4 / v$. Accordingly, $m_{0}=9.4, m_{v}=16.5, v=3.5$ and $m^{*}=54.3$.
} 
Table 1: Numerical Specification of the Economy

\begin{tabular}{lccl}
\hline \hline description & notation & value & based on \\
\hline human metabolism & $B_{0}$ & 70 & Kleiber (1932) \\
Kleiber's law & $b$ & $3 / 4$ & Kleiber (1932) \\
equilibrium body-size & $m^{*}$ & 54.3 & avg. empirical sample (Section 5) \\
relative child size after weaning & $\mu$ & 0.165 & WHO \\
energy for pregnancy and lactation & $\rho$ & 0.11 & Mays (2010), Butte and King (2007) \\
energy requirement for body growth & $d$ & 0.34 & West et al. (2001) \\
standardized size of body cell & $a$ & 0.59 & implied \\
time requirement of child rearing & $\tau$ & 0.06 & Deaton and Muellbauer (1986) \\
labor share & $\alpha$ & 0.65 & Clark (2007) \\
body size elasticity in production & $\phi$ & 0.25 & Strauss (1986) \\
utility weight for non-food & $\beta$ & 4.5 & Clark (2007) \\
utility weight for children & $\gamma$ & 4.0 & Brown et al. (2004) \\
life-time income per adult at subsistence & $y^{*}$ & 7058 & Maddison (2003) \\
population density & $L^{*}$ & 1.0 & normalized \\
productivity & $A$ & 2425 & implied \\
energy exchange rate & $\epsilon$ & 0.34 & implied \\
length of a period in years & $\psi$ & 15 & Clark (2007) \\
\hline \hline
\end{tabular}

in Appendix A. We assume that consumption of the parent beyond metabolic needs (that is $p$ ) consists of non-food consumption and set $\beta=4.5$ such that the food expenditure share at the steady-state is $80 \%$ in line with empirical observations for poor societies in history (Clark, 2007).

To calibrate the impact of body size on productivity (i.e., $\phi$ ) we proceed in two steps. As a first step, we observe that productivity can be related to nutritional needs. Using the production function (10) and Kleiber's law (1), we obtain:

$$
\log \left(y_{t}\right)=\log (Z)+\frac{\phi}{b} \log \left(B_{t}\right)+(1-\alpha) \log (X / L)
$$

with $\log (Z) \equiv \log (A)+(\phi / b) \log \left(B_{0}\right)$. Assuming that energy needs are a reasonable proxy for energy consumption we can employ Strauss' (1986) estimates for the impact of nutrition on farm productivity to calibrate $\phi$. Strauss finds that the elasticity of farm output with respect to nutrition is about $1 / 3$ (with a standard error of 0.11 ), which in theory reflects $\phi / b$. Since $b$ is $3 / 4$, it follows that a reasonable value for $\phi$ is $1 / 4$, which we will use below.

We normalize the (initial) steady-state size of the population of adults to unity. Suppose that steady-state output per capita is 400 (international dollars) per year as estimated for most European countries during the early and high Middle Ages (Maddison, 2003). Then, during the period of adulthood income is $\$ 7059$ i.e. $15 \cdot 400 /(1-\tau)$. Using the values for $m^{*}, L^{*}$, and $y^{*}$ we get an estimate of (initial) factor productivity $A$ of 3471 . We determine the remaining two parameters, $a$ and $\epsilon$, by solving the numerically specified model at $m^{*}$ and $L^{*}$. This provides the estimates $a=0.58$ and $\epsilon=0.36$. Table 1 summarizes the notation, the numerical specification, and the sources it is based on.

4.3.2. Dynamic Properties of the Model. Consider a permanent increase in productivity $A$ by three percent (equivalent to a 0.2 percent annual productivity growth during the 15 years 
of period 1), which could be the result of technological change in agriculture. In the phase diagram the parameter change leads to an upward shift of both the $\Delta m=0$-locus and the $\Delta L=0$-locus leaving the intersection at $m^{*}$ unchanged. As a consequence the economy leaves the initial equilibrium in north eastern direction. People react on the improved conditions by having more kids and nourishing them better. Adjustment dynamics shown by solid lines in Figure 4 set in.

Figure 4: Impulse Responses after Permanent Productivity Shock
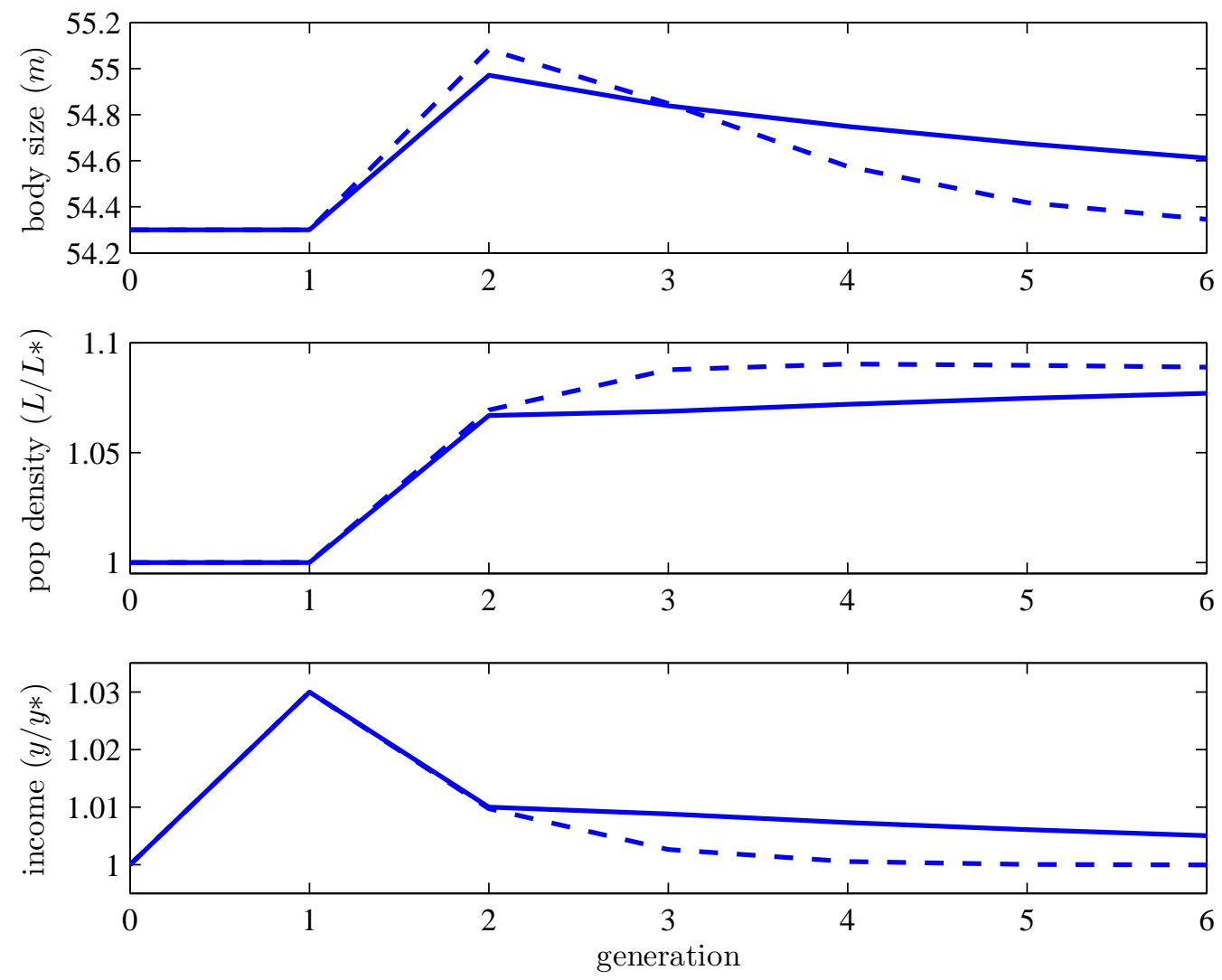

Adjustment dynamics after permanent increase of productivity by 3 percent in generation 1 (equivalent to a 0.2 percent annual productivity growth between generation 1 and generation 2). Solid lines: benchmark economy. Dashed lines: alternative economy with body size in the utility function (See Appendix). All parameters values from Table 1.

Higher productivity leads to a temporary rise in body size and a permanent rise of population size (and density). The shown impulse responses document a high degree of persistence in body size with a half-life of about five generations. Only gradually does rising fertility reduce income per capita and body size. Although the productivity shock expires in period two, children of period-two mothers grow up to be almost as large as their mothers. This means that period-three adults display above steady-state labor productivity such that income per capita falls less drastically than it would in a standard Malthusian model without bodysize related productivity gains. Without the physiological check at work (i.e. if $b$ where smaller than $\phi$ ), the productivity gains through elevated body mass would be so strong that 
income would never decline and the (then unstable) economy would continue to expand with perpetually rising stature and fertility.

While stability is a feature driven by the physiological check, speed and shape of adjustment dynamics depend on the numerical specification of other model parameters as well. For example, in an earlier version of this research (Dalgaard and Strulik, 2010) we document that for $\beta=0$ (i.e. when parental consumption beyond subsistence needs is ignored) there can be adjustment dynamics in cycles. ${ }^{15}$

Impulse responses for the utility-from-body-size model (cf. Appendix B) are shown by dashed lines in Figure 4. To produce it we took the same parameter values as for the baseline model (from Table 1). Besides a re-estimation of $a$ (which decreases from 0.58 to 0.36 ) and $\epsilon$ (which decreases from 0.36 to 0.35 ) the extended model entails also a (mild) re-assessment of the speed of adjustment. Dashed lines in Figure 4 show impulse responses for the utility-frombody-size model. From period three onwards adjustment dynamics are faster than suggested by the baseline model. Still, both models predict basically the same responses on impact for population size and for body size. Thus, especially over shorter time horizons (two to three generations), the results of the baseline model is a fairly accurate approximation to the results stemming from the utility-from-body-size model.

These patterns of population and body size dynamics, are rather similar to what is found in the data. The long-run evolution of population trends are fairly familiar to historians and economists working on growth in the long run. Briefly, up until somewhere in the 19th century population growth was slow in Western European countries. Accordingly, for most of the preceding millennia, prior to the onset of the industrial revolution, the growth trajectory is slightly upward sloping with occasional disruptions, for example, those caused by the Black Death. Overall, the Western European population increased by about a factor of four from the first to the 17th century (Kremer, 1993).

Interestingly, for average European body size, i.e. stature, there was no trend visible during the Middle Ages. The study by Koepke and Baten (2005), drawing on height data derived from European skeletal remains, finds strong evidence in favor of oscillations in stature around a constant trend level of height (circa $170 \mathrm{~cm}$ ) during the last two millennia. Statistical tests reveal that the deviations from trend are significant. Komlos and Baten (2004) discuss evidence on body size deriving from historical sources and from various regions. This evidence broadly follows similar regularities compared with the data stemming from skeletons, albeit the period in question is much shorter (i.e., 18th century).

Taken together this evidence suggests that prior to the industrial revolution human societies witnessed step-wise increases in population (punctuated by occasional declines), while at the same time height exhibited very little trend in either direction (see also Clark, 2007). Instead, cyclical movements in height, around a constant trend, seem to have been the norm, in the very long-run.

\footnotetext{
${ }^{15}$ Overshooting behavior occurs in the sense that the second generation born after the shock is too large with respect to both population size and body size. Productivity is relatively low and - compared to period 1 after the shock - parents reduce fertility and investment in child quality, both of which remain nevertheless above pre-shock level. As a consequence of lower population density, income of the third generation is a little higher than income of the second generation and the system adjusts in damped oscillations towards its initial equilibrium of income and body mass.
} 


\section{Confronting the model With Data}

In this section we gauge the empirical value of the proposed model. In section 5.1. we begin by examining whether the model can account for the time series data on body size for Europe over the two millennia that preceded the fertility transition. Subsequently, in Section 5.2., we confront the models cross section predictions with data for a sample of less developed economies.

5.1. Physiological dynamics during Pre-industrial times. In the following we use available (but admittedly fragmentary) data to put the predictive quality of our model to a test. Specifically, we design the following experiment. We take the historical data on European population from Kremer (1993) and on body size (height) from Koepke and Baten (2005). We then calibrate in any century productivity $A$ such that the model values for $m_{t}, L_{t}, L_{t+1}$ match the historical data. Subsequently, we use the calibrated model (as specified in Table 1) along with the estimated time series for productivity to predict $m_{t+1}$.

Figure 5: Predicting Average Stature in Europe
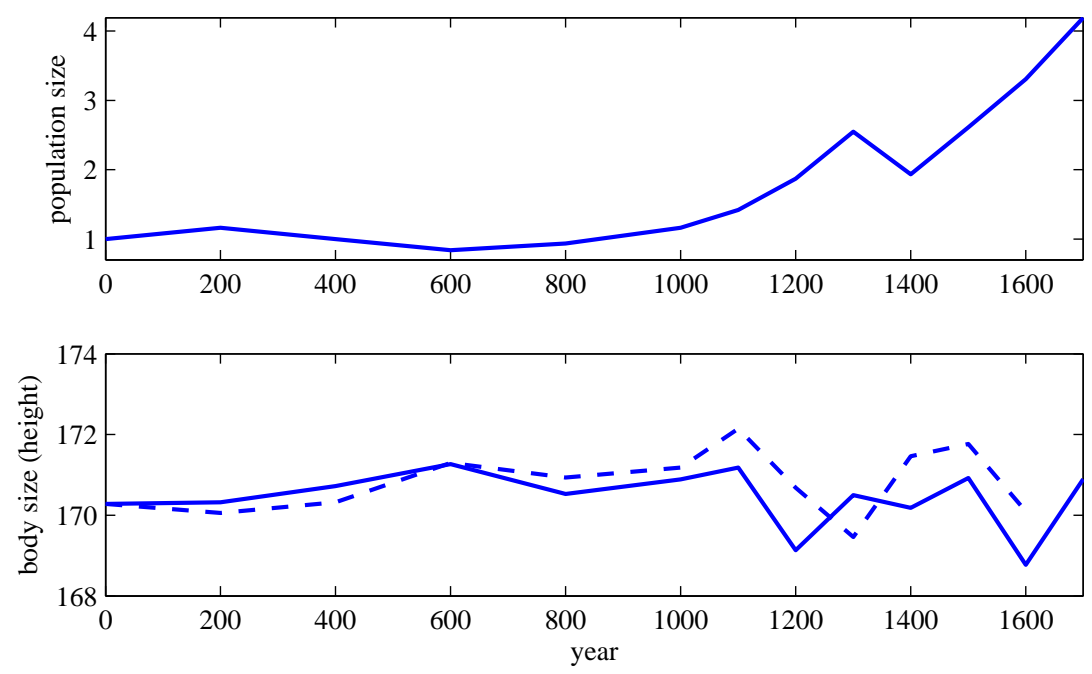

Solid lines show the historical time series according to Kremer (1993) and Koepke and Baten (2005). Productivity shocks are calibrated such that the model economy produces the historical evolution of population size. The calibrated model (from Table 1) and the imputed productivity series (for parameter $A$ ) are then used to predict the historical evolution of body size in Europe (dashed line).

In order to use and to compare with the historical data we have converted the historical height numbers into weight using the definition of the body mass index (BMI). After the simulation, body mass is re-converted by the same BMI into height and the predicted time series is compared with the empirical data. ${ }^{16}$ Admittedly, the data on height should be interpreted with care, as they are based on skeleton remains from a variety of archaeological

\footnotetext{
${ }^{16} \mathrm{BMI}$ is defined as height (in meters) divided by the square root of weight (in $\mathrm{kg}$ ). Ideally we would like to compare the models' predictions directly to historical data on body size in the sense of weight; to our knowledge such data does not exist, unfortunately.
} 
excavations, which may not be equally representative. Still, this is to our knowledge the only source of intertemporally comparable data on body size, which spans the period of European history where Malthusian forces arguably were of first order importance.

Figure 5 shows the result of this exercise. By construction, the imputed productivity change fully explains the empirical time series of population growth and thus the secular increase of population growth by about a factor of four over the 17 centuries. These productivity changes induce the model to predict mean-reverting fluctuations of body size that match the historical data reasonably well. In particular, for most centuries the model correctly predicts the direction of change for body size. The only period in history where the model fails drastically is around the time of the Black Death episode. The explanation here is very intuitive. The big slump of population growth in the 14th century was predominantly caused by sharply increasing mortality (instead of productivity changes). Since there is no explicit role for mortality in the model, it misinterprets the slump as caused by falling productivity and gets the stature cycle wrong. After the Black Death episode the model resumes to predict changes of body size reasonably well.

5.2. Physiology and Comparative Development. The proposed theory holds several steady state predictions that can be taken to the data:

(1) Population density should be higher in societies with greater productivity.

(2) GDP per worker should be unaffected by productivity.

(3) Average body size should be unaffected by productivity (cf. equation 13a)).

(4) In societies where individuals are larger, GDP per worker should be higher (cf. equation $(13 \mathrm{c}))$.

(5) Conditional on productivity: In societies where individuals are larger, population density should be lower (cf. equation (13b)).

While the first two predictions also follow from the standard Malthusian model (see Ashraf and Galor, 2011; henceforth: AG) the remaining three are unique to the theory developed above (see Proposition 2 and Corollary 1). The next section lays out our empirical specification after which we discuss our data in section 5.2.2.; in Section 5.2.3 we report our cross-country regression results. Finally, in Section 5.2.4 we further scrutinize the model's predictions using a sample of contemporary hunter-gatherer societies.

5.2.1. Empirical Specification. In confronting the model with the data, we follow AG in examining its steady state predictions. This means estimating, as a first step, an equation of the following form:

$$
\log \left(Z_{i}\right)=\alpha_{0}+\alpha_{1} \log \left(A_{i}\right)+\gamma^{\prime} \boldsymbol{\Gamma}_{i}+\varepsilon_{i}
$$

where $i$ is a country index, $\log \left(Z_{i}\right)=\{\log$ population density, log body size (kg), $\log$ GDP per worker, and $\log$ labor productivity in agriculture $\}, \log \left(A_{i}\right)$ is productivity, whereas $\boldsymbol{\Gamma}_{i}$ contains additional controls. The prior is that $\alpha_{1}>0$ when population density constitutes the left hand side variable, whereas $\alpha_{1}=0$ when either body size or income enters the left hand side of the equation (cf. predictions 1-3). Aside from providing out-of-sample testing of the results in $\mathrm{AG}$, the central test is whether productivity works to elevate body size. Common sense might suggest it should, mediated by higher levels of nutrition perhaps, whereas our model predicts that body size should be left unaffected by higher levels of productivity.

As a second step, we examine further implications of the model by estimating an equation of the following form

$$
\log \left(Z_{i}\right)=\beta_{0}+\beta_{1} \log \left(m_{i}\right)+\beta_{2} \log \left(A_{i}\right)+\gamma^{\prime} \boldsymbol{\Gamma}_{i}+\varepsilon_{i}
$$


for $\log \left(Z_{i}\right)=\{\log$ population density, log GDP per worker, log labor productivity in agriculture $\}$, and $m$ is body size measured in $\mathrm{kg}$. Our prior is that $\beta_{1}<0$, when the left hand side variable is population density, reflecting the physiological check, and that $\beta_{1}>0$ when income enters the right hand side of the equation, reflecting that greater subsistence needs are reflected in greater income (cf. predictions 4-5). Naturally, we expect $\beta_{2}$ to remain positive in the population density regression, and insignificant when attention is turned to the income models.

In choosing relevant controls to be included in $\Gamma_{i}$ we essentially follow $A G$, who examine the empirical implications of a basic Malthusian model on cross-country data. Still, in the first specification we cannot rule out a priori that our OLS estimates for $\alpha_{1}$ might be tainted by omitted variable bias. To alleviate this cause for concern as much as possible, we provide additional robustness checks in the Appendix. Our precise choice of controls, and those invoked in the robustness checks, are described below.

In the second specification reverse causality may be an additional concern. That is, a positive correlation between income and body size may reflect the impact of income on body size (weight), rather than the influence from body size on subsistence needs and thus income. Similarly, one might theorize that a negative correlation between population density and body size could be due to a negative impact from density on body weight, perhaps mediated by disease incidence, rather than a negative impact of body size on population density, mediated by elevated metabolic costs of child rearing. Below we try to deal with this form of endogeneity by way of IV estimation. The details on the identification strategy are given below. In addition to the IV procedure we also check the OLS results with an extended set of controls, and, by invoking data from a cross-section of contemporary hunter-gatherer societies.

5.2.2. Data. A major obstacle in testing the predictions of the model is data on body size. To be sure, an analysis akin to that of AG is infeasible as data on body size (i.e., weight) during the pre-industrial era does not exist. ${ }^{17}$ However, since the theory strictly speaking applies to any economy that has yet to undergo the fertility transition we can make progress by focusing on more recent developments. That is, we can try to test the predictions of the model across countries where the fertility transition only very recently took place, or still may be underway.

In determining which countries only "recently" went through the fertility transition we rely on the work of demographers. Specifically, Reher (2004) dates the timing of the fertility transition for countries around the world. In our analysis we focus on the group Reher classifies as "latecommers", which involves countries that underwent the fertility transition in 1980 or later. ${ }^{18}$ Given the constraint that we require data on body size (measured in $\mathrm{kg}$ ), which we obtained from the Demographic and Health Surveys (DHS), we are left with a sample of 38 "latecommers" for which data on body size is available. The data on body size is derived from the maternal health module in DHS, implying that our measure for average body size relates to that of females in the age group 15-49. Hence, female body size will serve as a proxy variable for average stature in the population at large. Throughout we focus on observations

\footnotetext{
${ }^{17}$ Historical height data is similarly very scarce for this period, perhaps covering a mere handful of countries; too scarce to form the basis of an regression analysis.

${ }^{18}$ Reher (2004) classified the countries of the world as either "forerunners", "followers", "trailers" or "latecommers"; we focus on the last group. See data appendix for details on how Reher (2004) dates the fertility transition.
} 
on income, density and body size in ca. $2000 .^{19}$ Details on data sources and a list of the countries in our sample, are found in Appendix C.

In Table 2 we provide some background information for the countries in our sample. The typical country underwent the fertility transition in 1990; only in two countries did the transition occur, according to Reher, in $1980 .{ }^{20}$ As is evident, all the countries in question are poor. In 2000 per capita income (PPP\$) ranged from less than one dollar per day to about $23 \mathrm{PPP} \$$ per day, with a median of roughly 4 PPP\$ per day. The picture is very similar if we focus on labor productivity in agriculture (constant 2000 US\$). These numbers suggest that a Malthusian framework may not be a bad description of the economies at hand. Moreover, and perhaps unsurprisingly, most of the countries in our sample are African; 31 out of the total of 38 .

Table 2: Descriptive Statistics for Country Sample

\begin{tabular}{lccccc}
\hline \hline Variable & Min & Max & Median & Mean & Std \\
\hline Year of fertility decline & 1980 & 2000 & 1990 & 1990 & 7.02 \\
GDP per capita, 2000 (PPP) & 312 & 8504 & 1401 & 1937 & 1605 \\
GDP per worker in agr, 2000 (constant US\$) & 81 & 2950 & 332 & 534 & 610 \\
Weight (kg) & 42.41 & 65.10 & 54.53 & 54.29 & 4.43 \\
Population density, 2000 & 0.02 & 10.5 & 0.53 & 0.97 & 1.78 \\
\hline \hline
\end{tabular}

Notes: GDP per capita (PPP\$) is from PWT 6.3. See Appendix C for data description and sources of the remaining variables.

As noted above, we largely follow $\mathrm{AG}$ in selecting controls (i.e., $A_{i}, \boldsymbol{\Gamma}_{i}$ ). Our prime proxy for productivity is a measure of soil quality, which captures how adequate soil conditions are (i.e., soil fertility, depth etc) for growing rainfed crops. As additional baseline controls we follow AG by using distance from ice-free coast, fraction of country area within $100 \mathrm{~km}$ of ice-free coast and log (absolute latitude). Finally, we add an Africa dummy to the model. ${ }^{21}$

In our robustness checks we add controls employed by AG in their robustness checks, and additional ones that have been put forward as particularly important in an African context (since most countries in our sample are African). These additional controls fall in three categories: Additional geography controls (terrain ruggedness; tropical area; island dummy), colonial history (former British colony, former French colony and ethno-linguistic

\footnotetext{
${ }^{19}$ We focus on the year 2000 as a compromise between the need to have maximum country coverage, and at the same time data that speaks to the "Malthusian" regime. In 2000 the youngest women surveyed in DHS are 15 years old, which means that they were born around 1985. Accordingly, in year 2000 the data on body weight relates to individuals who (generally speaking) were born prior to the fertility decline, or roughly at the year of the decline. This makes it more plausible that the Malthusian mechanisms of our model may be adequate description of the data.

${ }^{20}$ It is worth observing that Reher (2004) codes countries that have still to undergo the fertility transition as "2000". Hence, the "true" maximum value for the year of the fertility decline is not 2000.

${ }^{21}$ Our specification differs from AG's in two minor ways. First, AG invoke a full set of continental fixed effects. In our case this makes little sense, as most of our sample is African countries anyway. Second, AG also includes a control for the timing of the Neolithic revolution, as an additional proxy for productivity. We include this variable in our robustness checks, though we use a version which is adjusted for post Colombian migration (see Putterman and Weil, 2010). While time since the Neolithic is a significant determinant of population density in e.g. 1500 it appears to be of limited importance in 2000, as seen from our appendix tables.
} 
fractionalization in 1985) and ancient history (time since Neolithic, migration adjusted). Our main results are robust to the inclusion of these controls on top of the baseline ones.

Finally, we obtained data on body size (weight in kg) and population density for 29 huntergatherer societies from Walker and Hamilton (2008). In this context body size also pertains to females but represents population averages. Density and body size were observed in the same year. From Walker and Hamilton we also obtained some information about the structural characteristics of the individual societies (e.g., ecology, latitude etc), which we include in the regressions. Naturally, data on income is not available. Moreover, we do not have a direct measure of how productive the hunter-gatherer's environment's are. In practise we expect that some of our geography controls will capture differences in this respect, but absent a direct productivity measure we cannot test Predictions 1-4. Hence, the main value of the huntergatherer sample is that it provides an opportunity to check our cross-country estimates for $\beta_{1}$, which pertains to the physiological check (i.e., Prediction 5). The question is whether our cross-country estimates of the strength of the physiological check corresponds to what one finds in a cross-section of hunter-gatherer societies that surely can be regarded as "subsistence societies". In contrast to our cross-country sample, the hunter-gatherer sample effectively spans the globe: ranging from the deserts of Australia to the polar tundra of Alaska.

Table 3. Testing the Model's Steady-State Predictions

\begin{tabular}{lllllllll}
\hline \hline & $(1)$ & $(2)$ & $(3)$ & $(4)$ & $(5)$ & $(6)$ & $(7)$ & $(8)$ \\
\hline & $\log (L / X)$ & $\log (L / X)$ & $\log (m)$ & $\log (m)$ & $\log (y)$ & $\log (y)$ & $\log \left(y_{a}\right)$ & $\log \left(y_{a}\right)$ \\
& & & & & & & & \\
Log soil & $1.094^{* * *}$ & $1.030^{* * *}$ & -0.029 & -0.026 & -0.023 & -0.161 & 0.017 & -0.132 \\
& $(0.200)$ & $(0.227)$ & $(0.021)$ & $(0.028)$ & $(0.149)$ & $(0.115)$ & $(0.150)$ & $(0.151)$ \\
Log latitude & & -0.288 & & -0.005 & & -0.075 & & -0.143 \\
& & $(0.258)$ & & $(0.014)$ & & $(0.139)$ & $(0.143)$ \\
Distance to coast & & 0.149 & & -0.075 & & $-1.095^{* *}$ & -0.576 \\
& & $(0.768)$ & & $(0.049)$ & & $(0.506)$ & & $(0.444)$ \\
\% Near coast & & 0.009 & & -0.001 & & -0.009 & & 0.001 \\
& & $(0.009)$ & & $(0.001)$ & & $(0.007)$ & & $(0.007)$ \\
Africa & & -0.941 & & 0.058 & & $-0.667^{*}$ & & -0.871 \\
& & $(0.558)$ & & $(0.064)$ & & $(0.391)$ & & $(0.531)$ \\
Constant & $-6.850^{* * *}$ & $-5.527^{* * *}$ & $4.089^{* * *}$ & $4.090^{* * *}$ & $8.346^{* * *}$ & $10.223^{* * *}$ & $5.834^{* * * *}$ & $7.587^{* * *}$ \\
& $(0.706)$ & $(1.261)$ & $(0.070)$ & $(0.117)$ & $(0.543)$ & $(0.920)$ & $(0.476)$ & $(0.922)$ \\
\hline Observations & 38 & 38 & 38 & 38 & 38 & 38 & 36 & 36 \\
R-squared & 0.371 & 0.505 & 0.071 & 0.205 & 0.001 & 0.272 & 0.000 & 0.276 \\
\hline \hline
\end{tabular}

Notes: (i) The dependent variable in Column 1 and 2 is log population density in 2000; in 3 and 4 it is log body size (kg); 5 and 6 it is log GDP per worker, and in in Column 7 and 8 it is $\log$ GDP per worker in agriculture. (ii) "Log soil" is a measure of soil quality; "log latitude" is log of absolute latitude; "distance to coast" captures average distance in km from coast; "\% Near coast" is fraction of land area within $100 \mathrm{~km}$ of coast; "Africa" is a dummy variable. See Appendix C for further details. (iii) Robust standard errors in parentheses; ${ }^{* * *} p<0.01,{ }^{* *} p<0.05,{ }^{*} p<0.1$.

5.2.3. Results: Cross-country. Table 3 reports our baseline results from estimating equation (16) by OLS. As seen from column 1 and 2, soil quality is significantly and positively correlated with population density in 2000. At the same time, however, soil quality is insignificantly correlated with both income and body size. It is perhaps particularly revealing to see that labor productivity in agriculture is insignificantly correlated with soil quality in our sample of countries. These results are consistent with Proposition 2, and the results obtained by AG in a broader world sample pertaining to the period 1 C.E. to 1500 C.E. 
In order to check that our results are not carried by outliers the models were re-estimated by an outlier robust estimator (Least-absolute-deviations, LAD). The LAD estimates are very similar to the OLS results, and available upon request. In Appendix Table 3.A we extend the list of controls with no qualitative impact on the key results reported above. Finally, to limit the risk that our results are tainted by continent-specific heterogeneity, we checked whether the results change if we confine attention to the African continent. They do not, and the results are available upon request.

In Table 4, we estimate equation (17) by way of OLS and 2SLS. The 2SLS exercise has a simple motivation: simultaneity, as discussed above. In order to address this issue we invoke an instrument for body size: height. The logic is simple. Whereas body size, in the sense of weight, is variable in the short run - and thus potentially affected by current conditions - height is strongly predetermined and thus very unlikely to be affected by current income or population density. Moreover, as discussed in Section 4, height is partly genetically determined, for which reason this instrument may allow us to isolate variations in body weight attributable to deep physiological factors, such as those embedded in the model parameter $d$. In any event, using height as an instrument for body weight ensures that our estimates cannot be attributed to reverse causality.

Table 4. Physiological Links: Cross-country Evidence

\begin{tabular}{lllllll}
\hline \hline & $(1)$ & $(2)$ & $(3)$ & $(4)$ & $(5)$ & $(6)$ \\
\hline \multirow{4}{*}{$\log (L / X)$} & $\log (L / X)$ & $\log (y)$ & $\log (y)$ & $\log \left(y_{a}\right)$ & $\log \left(y_{a}\right)$ \\
& OLS & 2 SLS & OLS & 2 SLS & OLS & 2 SLS \\
\hline Log soil & $-4.558^{*}$ & $-6.534^{*}$ & $3.575^{* * *}$ & $4.099^{* *}$ & $6.049^{* * *}$ & $6.405^{* * *}$ \\
& $(2.520)$ & $(3.822)$ & $(1.140)$ & $(2.060)$ & $(1.431)$ & $(2.367)$ \\
Log latitude & $0.912^{* * *}$ & $0.860^{* * *}$ & -0.068 & -0.054 & 0.043 & 0.054 \\
& $(0.277)$ & $(0.228)$ & $(0.145)$ & $(0.106)$ & $(0.147)$ & $(0.119)$ \\
Distance to coast & -0.312 & -0.323 & -0.056 & -0.053 & -0.112 & -0.110 \\
& $(0.261)$ & $(0.205)$ & $(0.138)$ & $(0.108)$ & $(0.126)$ & $(0.100)$ \\
\% Near coast & -0.191 & -0.339 & $-0.828^{*}$ & $-0.789^{* *}$ & -0.063 & -0.032 \\
& $(0.796)$ & $(0.686)$ & $(0.466)$ & $(0.371)$ & $(0.397)$ & $(0.356)$ \\
Africa & 0.006 & 0.005 & -0.007 & -0.007 & 0.006 & 0.007 \\
& $(0.010)$ & $(0.008)$ & $(0.006)$ & $(0.005)$ & $(0.005)$ & $(0.004)$ \\
Constant & -0.675 & -0.559 & $-0.876^{* *}$ & $-0.907^{* * *}$ & $-1.248^{* * *}$ & $-1.271^{* * *}$ \\
& $(0.492)$ & $(0.497)$ & $(0.343)$ & $(0.253)$ & $(0.344)$ & $(0.230)$ \\
& 13.113 & 21.197 & -4.396 & -6.539 & $-17.224^{* * *}$ & $-18.684^{*}$ \\
First-stage F value & & 13.93 & & 13.93 & & 13.79 \\
Observations & 38 & 38 & 38 & 38 & 36 & 36 \\
R-squared & 0.568 & 0.556 & 0.425 & 0.422 & 0.582 & 0.581 \\
\hline \hline
\end{tabular}

Notes:(i) The dependent variable in Column 1 and 2 is log population density in 2000; in 3 and 4 it is log GDP per worker; in Column 5 and 6 it is $\log$ GDP per worker in agriculture. (ii) " $\log (m)$ is $\log$ body size in $\mathrm{kg}$; "Log Soil" is a measure of soil quality; "log latitude" is log of absolute latitude; "Distance to coast" captures average distance in $\mathrm{km}$ from coast; "\% Near coast" is fraction of land area within $100 \mathrm{~km}$ of coast; "Africa" is a dummy variable. See Appendix C for further details. (iii) Column 1, 3 and 5 are estimates by OLS; Column 2, 4 and 6 are 2SLS estimates, where $\log (m)$ is instrumented by $\log$ height (in meters). (iv) Robust standard errors in parentheses; ${ }^{* * *} p<0.01$, ${ }^{* *} p<0.05,{ }^{*} p<0.1$. (v) The reported first stage $\mathrm{F}$ value refers to the Kleibergen-Paap F statistic. 
Naturally, the obtained point estimate for body mass, when height is used as an instrument, may still be biased if height is correlated with density and income conditional on body weight, as a result of omitted variables that are correlated with height. As above we provide separate checks of omitted variable bias with an extended set of controls.

Turning to the results we continue to find that soil quality is significantly and positively correlated with population density, yet insignificantly linked to our income measures (see Figures A.1-A.2 in the appendix for an added variables plot).

Critically, from the point of view of the proposed theory, we find evidence in favor of the physiological check: In column 1 body size is negatively correlated with density, a result which cannot be ascribed to reverse causality as seen from column 2. One may observe from the reported F-value that height is a strong instrument for body size (i.e., weight). While the point estimate increases when 2SLS is invoked it is statistically insignificantly different from its OLS counterpart. Conditional on the exclusion restriction this suggests that reverse causality is only a minor problem. This negative link between population density and body size is consistent with a key implication of the theory. Namely, that higher metabolic costs of child-rearing serves to limit fertility, and thus in the long-run, population density (see Figure A.3 for an added variables plot).

In columns 3-6 we find evidence in favor of a positive impact from body size on labor productivity. This is consistent with the theory, according to which the positive link is due to higher body size related productivity and a higher land-labor ratio (cf. column 1 and 2). In the long-run, therefore, income is sufficient to cover the higher metabolic needs of citizen's of larger body size (see Figure A.4 for an added variables plot).

While the 2SLS estimates in column 2, 4 and 6 show that the results cannot be ascribed to reverse causality, the issue of omitted variable bias cannot be ruled out a priori. As in the baseline model we therefore also checked the OLS results against the inclusion of a larger set of controls. These results are found in Appendix Table 4.A. The results are very similar to those reported in Table 4, giving some assurance that omitted variables are not driving the results. We also re-estimated the models in Table 4 on a sample consisting solely of African countries. Despite a reduction of sample size by nearly 25 percent the key IV results, involving the negative link between body size and population density (the physiological check) as well as the positive link between body size and productivity, still obtains. These additional regression results are available upon request.

Overall we view these results, taken in their totality, as encouraging from the point of view of the proposed theory. The results reported in Tables 3 and 4 support predictions 1-5, of which 3-5 are unique to the theory developed above. Particularly important are the results that testify to a trade-off between population density and average body size, as it constitutes a clear-cut prediction of the model, ultimately reflecting the physiological check: larger parents have smaller families due to elevated metabolic costs from child rearing. This is, according to the theory, the central mechanism that prevents the take-off from occurring, despite the fact that parents invest in child quality; i.e., nutrition (main text) or child body size (Appendix B).

5.2.4. Results: Hunter-Gatherers. The data used in this section was compiled by anthropologists (Walker and Hamilton, 2008). As noted in the Introduction a size-number trade off is well established in biology and anthropology. What is less obvious from this literature however (and not reported by Walker and Hamilton) is the slope of the negative link between 
population density and average body size; this estimate is naturally of some interest in light of our independent estimates in Table 4.

Moreover, based on the information reported in Walker and Hamilton (2008, Table 1) it is possible to construct additional controls which may have influence on the correlation between body size and density. In particular, it is possible to test the robustness of the link between body size and density to the inclusion of log absolute latitude, a dummy variable capturing whether the society in question is coastal as well as whether the hunter-gatherer tribe is located in Africa. This set of controls largely mimics our preferred specification, which in turn is taken from AG. Unfortunately we do not have an obvious measure of productivity. But we can perform a series of robustness checks by adding further controls for the type of ecology which surrounds the individual tribes, as this is rather varied, ranging from Australian deserts to the polar tundra of Alaska. Hopefully these added controls may capture "productivity". ${ }^{22}$

Table 5: The Physiological Check: Hunter-Gatherers

\begin{tabular}{|c|c|c|c|c|c|c|c|}
\hline & $(1)$ & $(2)$ & $(3)$ & $(4)$ & $(5)$ & $(6)$ & $(7)$ \\
\hline $\log (m)$ & $\begin{array}{l}-5.743^{* * *} \\
(0.956)\end{array}$ & $\begin{array}{l}-4.877^{* * *} \\
(1.232)\end{array}$ & $\begin{array}{l}-5.397^{* * *} \\
(1.267)\end{array}$ & $\begin{array}{l}-4.317^{* * *} \\
(1.338)\end{array}$ & $\begin{array}{l}-5.818^{* * *} \\
(1.266)\end{array}$ & $\begin{array}{l}-4.864^{* * *} \\
(1.246)\end{array}$ & $\begin{array}{l}-4.153^{* * *} \\
(1.402)\end{array}$ \\
\hline Log latitude & & $\begin{array}{l}-0.253 \\
(0.252)\end{array}$ & $\begin{array}{l}-0.092 \\
(0.292)\end{array}$ & $\begin{array}{l}-0.205 \\
(0.250)\end{array}$ & $\begin{array}{l}-0.392 \\
(0.263)\end{array}$ & $\begin{array}{l}-0.237 \\
(0.268)\end{array}$ & $\begin{array}{l}-0.024 \\
(0.295)\end{array}$ \\
\hline Coastal & & $\begin{array}{l}1.389^{*} \\
(0.748)\end{array}$ & $\begin{array}{l}1.330 \\
(0.815)\end{array}$ & $\begin{array}{l}1.575^{*} \\
(0.790)\end{array}$ & $\begin{array}{l}1.466^{*} \\
(0.779)\end{array}$ & $\begin{array}{l}1.308 \\
(0.859)\end{array}$ & $\begin{array}{l}1.840^{* *} \\
(0.715)\end{array}$ \\
\hline Africa & & $\begin{array}{l}-0.520 \\
(0.440)\end{array}$ & $\begin{array}{l}-0.148 \\
(0.632)\end{array}$ & $\begin{array}{l}-0.523 \\
(0.443)\end{array}$ & $\begin{array}{l}-0.546 \\
(0.445)\end{array}$ & $\begin{array}{l}-0.496 \\
(0.464)\end{array}$ & $\begin{array}{l}-0.574 \\
(0.495)\end{array}$ \\
\hline Desert & & & $\begin{array}{l}-0.983 \\
(0.916)\end{array}$ & & & & \\
\hline Tropical & & & & $\begin{array}{l}0.451 \\
(0.472)\end{array}$ & & & \\
\hline Polar & & & & & $\begin{array}{l}1.237^{*} \\
(0.648)\end{array}$ & & \\
\hline Savanna & & & & & & $\begin{array}{l}0.189 \\
(0.434)\end{array}$ & \\
\hline Western Offshoots & & & & & & & $\begin{array}{l}-0.999 \\
(0.803)\end{array}$ \\
\hline Observations & 29 & 29 & 29 & 29 & 29 & 29 & 29 \\
\hline R-squared & 0.426 & 0.560 & 0.604 & 0.573 & 0.598 & 0.563 & 0.608 \\
\hline
\end{tabular}

Notes: (i) The dependent variable in all columns is log population density. (ii) Estimates by OLS; Robust standard errors in parentheses ${ }^{* * *} p<0.01,{ }^{* *} p<0.05,{ }^{*} p<0.1$. (iii) All regressions contain a constant term. (iii) $\log (m)$ is $\log$ average weight in $\mathrm{kg}$; log latitude is the log of absolute latitude; Coastal is a dummy which takes on the value 1 if the society is coastal; Africa is a continent dummy; Tropical, Polar and Savanna takes on the value 1 if the tribe is living in these kinds of ecological systems, and Western Offshoots takes on the value 1 if the tribe is living in either USA or Australia. Data source: Walker and Hamilton (2008).

Table 5 reports the results from estimating equation (17). In the first column we study the pure correlation between density and average population size, and in column 2 we run

\footnotetext{
${ }^{22}$ Still, there is a reason to believe that the cross-society variation in productivity may be minor. Specifically, one may hypothesize that these societies remain hunter-gatherers precisely because - at their exact location - the environment is highly productive for the purpose of hunting and gathering. Hence, if these societies uniformly are highly productive (from the perspective of hunting and gathering) the lack of a control for productivity is less of a problem.
} 
the specification which comes the closest to mimicking the baseline specification in the crosscountry analysis. The next five columns then add dummy variables capturing variation in local ecology. In every case body size is significantly and negatively correlated with population density as expected.

The key finding, however, is that the size of the estimate for $\log (m)$ nearly coincides with those obtained in Table 4. In particular, in our baseline specification of Table 4 (column 1) we obtain an estimate of -4.56 , whereas the result across hunter-gatherers, in a very similar specification (column 2), is -4.88 .

The fact that we are able to detect a similar data pattern - down to point estimates - in these two very different samples suggests that whatever mechanism is generating the pattern is highly pervasive. We believe a good candidate mechanism is the "physiological check", which, according to the proposed theory was critically important in preventing income from rising during most of human existence. If income temporarily rose, parents responded by increasing family size and by offering their children better nutrition. In so doing, however, parents inadvertently increased the metabolic costs of child rearing for their offspring. In the absence of further positive income shocks, the next generation was thus forced to reduce family size and nutrition per child. As a result, temporary gains in body size eroded and income stagnated.

\section{Conclusion}

The theory developed in the present paper proposes that child quality investments have been made throughout history. These quality investments in child nutrition were productive and served to elevate individual productivity. Nevertheless, in the long run income stagnated. We hypothesize that the state of stagnation persisted due to a "physiological check": when body size increases subsistence requirements grow, which limits further nutritional advances and stabilizes the economic system around an endogenously determined subsistence boundary. We argue this is a key mechanism in explaining the absence of per capita income growth, which characterized most of human history, and represents a fundamental reason why episodes of technological change did not instigate rising body size and labor productivity. In fact, as shown above, with quality investments taking place the Malthusian positive check is not sufficient to equilibrate the economy.

The two millennia that preceded the fertility transition in Europe witnessed gradually rising population density, punctuated by occasional declines for disease related reasons. At the same time, however, body size did not exhibit any upward or downward trend. Our theory elucidates the mechanics behind this fact and the developed model is able to quantitatively account fairly well for the periodic changes in body size over the period in question.

While our theory predicts that income per capita should stagnate within countries, it also predicts that income per capita levels may well have differed across countries prior to the take-off. Differences across societies in body size, due to natural selection say, would imply persistent differences in nutritional requirements of adults. According to the proposed theory one would expect societies characterized by larger individuals to feature lower fertility, because the metabolic costs of child rearing inevitably will be larger. In the long run, therefore, one would expect to see societies where individuals are larger to be less populous. In addition, income per capita should be higher. Partly because size confers a productivity advantage, and partly because of a lower labor-land ratio. With a higher income per capita level larger bodies can be sustained. 
Our empirical analysis, using a cross-country sample of "latecomers" to the fertility transition does not allow us to reject these predictions. Within our sample of countries, which nests the poorest nations on earth, we find that larger body size (measured by weight) is positively associated with labor productivity and conditional on agricultural productivity, negatively linked to population density. At the same time, greater inherent productivity in agriculture is neither related to higher (agricultural) labor productivity nor to larger body size. 


\section{References}

Abdus S. and P. Rangazas, 2011. Adult Nutrition and Growth, Review of Economic Dynamics 14, 636-649.

Aiyar, S., C-J. Dalgaard and O. Moav, 2008. Technological progress and regress in preindustrial times, Journal of Economic Growth 13, 125-44

Ashraf, Q., and O. Galor. 2011. Dynamics and Stagnation in the Malthusian Epoch. American Economic Review 101, 2003-41.

Baker, M., 2008. A structural model of the transition to agriculture. Journal of Economic Growth, 13, 257-292

Becker G., 1960. An economic analysis of fertility. In: Demographic and economic change in developed countries. Conference of the Universities-National Bureau Committee for Economic Research, a Report of the National Bureau of Economic Research. Princeton University Press, Princeton, NJ, pp 209-240

Behrman, J.R. and M. Rosenzweig, 2004. Returns to birthweight, Review of Economics and Statistics 86, 586-601.

Brody, S., 1945, Bioenergetics and Growth, Van Nostrand-Reinhold, New York.

Brown, J., J. Gillooly, A. Allen, V.M. Savage and G. West, 2004, Towards a metabolic theory of ecology, Ecology 85, 1771-89.

Brinkman, H-J., J.W. Drukker, and B. Slot, 1988, Height and income: A new method for the estimation of historical national income series, Explorations in Economic History 25, 227-64.

Butte, N.F. and J.C. King, 2005, Energy requirements during pregnancy and lactation, Public Health Nutrition 8, 1010-1027.

Charnov, E.L., 1991, Evolution of life history variation among female mammals, Proceedings of the National Academy of Sciences of the United States of America 88, 1134-1137.

Charnov, E.L., 1993, Life History Invariants, Oxford University Press, Oxford.

Charnov, E.L. and S.K.M. Ernest, 2006. The offspring - size / clutch - size trade-off in mammals. The American Naturalist 167, 578-82.

Clark, G., 2007, Farewell to Alms: A Brief Economic History of the World, Princeton University Press.

Cole, T.J., 2000, Secular trends in growth, Proceedings of the Nutrition Society 59, 317-324.

Dalgaard, C-J. and H. Strulik, 2010. The Physiological Foundations of the Wealth of Nations. Discussion Paper No. 10-05 (University of Copenhagen).

Damuth, J., 1981, Population density and body size in mammals, Nature 290, 699-700.

Damuth, J., 1993. Cope's rule, the island rule and the scaling of mammalian population density, Nature 365, p. 748-50.

Deaton, A.S. and Muellbauer, J., 1986, On measuring child costs: With applications to poor countries, The Journal of Political Economy 94, 720-744. 
de Onis, M., Onyango, A.W., Borghi, E., Siyam, A.,Nishida, C. and Siekmann, J., 2007, Development of a WHO growth reference for school-aged children and adolescents, Bulletin of the World Health Organization 85, 660-667.

Douglas J.W.B. and H.R. Simpson, 1964, Height in relation to puberty family size and social class: A longitudinal study, The Milbank Memorial Fund Quarterly 42, 20-34.

Fogel, R.W., 1994, Economic growth, population theory, and physiology: The bearing of long-term processes on the making of economic policy, American Economic Review 84, 369-395.

Fogel, R.W., 1997, New findings on secular trends in nutrition and mortality: Some implications for population theory, in: Mark Rosenzweig and Oded Stark (eds.), Handbook of Population and Family Economics, Volume 1A, New York, Elsevier.

Galor, O., 2006, From stagnation to growth: Unified growth theory, in P. Aghion and S. Durlauf (eds.) Handbook of Economic Growth, North Holland, Amsterdam.

Galor, O., 2007, Discrete Dynamical Systems, Springer, Berlin, Heidelberg, New York.

Galor, O., 2010, The 2008 Lawrence R. Klein Lecture - Comparative Development: Insights from Unified Growth Theory, International Economic Review 51, 1-44.

Galor, O. and D. Weil, 2000, Population, technology and growth: From Malthusian stagnation to the demographic transition and neyond, American Economic Review 90, 806-828.

Galor, O., and O. Moav, 2002. Natural selection and the origin of economic growth. Quarterly Journal of Economics, 117, 1133-1191

Hagen, E.H., H.C. Barrett, and M.E. Price, 2006, Do human parents face a quality-quantity tradeoff? Evidence from a Shuar Community, American Journal of Physical Anthropology $130,405-418$.

Hansen, G. and E. Prescott, 2002, Malthus to Solow, American Economic Review 92, 12051217.

Kleiber, M., 1932, Body size and metabolism, Hilgardia 6, 315-353.

Koepke, N. and J. Baten, 2005a, The biological standard of living in Europe during the last two millennia, European Review of Economic History 9, 61-95.

Komlos, J., 1989. Nutrition and Economic Development in the Eighteenth-Century Habsburg Monarchy, Princeton University Press. social science history, Social Science History 28, 191-210.

Kremer, M., 1993, Population growth and technological change: One million B.C. to 1900, Quarterly Journal of Economics 108, 681-716.

Kuh, D.L. and M. Wadsworth M, 1989, Parental height: childhood environment and subsequent adult height in a national birth cohort, International Journal of Epidemiology 18, 663-668.

Kunitz, S., 1987, Making a long story short: A note on mens height and mortality in England from the first through the nineteenth centuries, Medical History 31, 269-80.

Lucas, R.E., Jr., 2000. Some Macroeconomics for the 21st Century. Journal of Economic Perspectives 14, pp. 159-168. 
Lucas, R.E. Jr., 2002, The industrial revolution: Past and future, in: Lucas, R.E. Jr., Lectures on Economic Growth, Cambridge, Massachusetts: Harvard University Press.

Maddison, A., 2003, The World Economy - A Millennial Perspective, OECD.

Mays, S., 2010, The effects of infant feeding practices on infant and maternal health in a medieval community, Childhood in the Past: An International Journal 3, 63-78. introduction of potatoes, Working Paper (Harvard University).

Nunn, N. and D. Puga, 2010. Ruggedness: The Blessing of Bad Geography in Africa, Forthcoming: Review of Economics and Statistics.

Prentice, A.M. and R.G. Whitehead, 1987, The energetics of human reproduction, Symposia of the Zoological Society of London 75, 275-304.

Putterman, L., 2008. Agriculture, Diffusion and Development: Ripple Effects of the Neolithic Revolution, Economica 75, 729-48

Putterman, L. and Weil, D.N., 2010. Post-1500 population flows and the long-run determinants of economic growth and inequality, Quarterly Journal of Economics 125, 1627-82.

Roff, D.A., 2002. Life History Evolution, Sunderland, MA, Sinauer Associates.

Ruff, C., 2002, Variation in human body size and shape. Annual Review of Anthropology 31, 211-232.

Sadurkis, A., N. Kabir, J. Wagner, and E. Forsum, 1988, Energy metabolism, body composition, and milk production in healthy Swedish woman during lactation, American Journal of Clinical Nutrition 48, 44-49.

Schneider, R., 1996, Historical note on height and parental consumption decisions, Economics Letters 50, 279-83.

Silventoinen, K., 2003, Determinants of variation in adult body height, Journal of Biosocial Science 35, 263-285.

Steckel, R., 1983, Height and per capita income, Historical Methods 16, 1-7.

Strauss, J., 1986. Does better nutrition raise farm productivity? Journal of Political Economy 94, 297-320.

Sharp, P. and Strulik, H. and Weisdorf, J., 2012. The determinants of income in a Malthusian equilibrium, Journal of Development Economics 97, 112-117.

Voigtländer, N. and Voth, H.J., 2009. The Three Horsemen of Growth: Plague, War and Urbanization in Early Modern Europe. CEPR Discussion Paper No. DP7275

Walker, R.S. and M.J. Hamilton, 2008, Life-history consequences of density dependence and the evolution of human body size, Current Anthropology 49, 115-12.2

Walker R., M. Gurven, O. Burger and M.J. Hamilton, 2008, The trade-off between number and size of offspring in humans and other primates, Proceedings of the Royal Society 275, 827-33.

Weil, D., 2007, Accounting for the effect of health on economic growth, Quarterly Journal of Economics 122, 1265-1306.

Weir, D.R., 1993, Parental consumption decisions and child health during the early French fertility decline: 1790-1914, Journal of Economic History, 259-74. 
West, G.B and J. H. Brown, 2005, The origin of allometric scaling laws in biology from genomes to ecosystems: Towards a quantitative unifying theory of biological structure and organization, Journal of Experimental Biology 208, 1575-92.

West G.B., J. H. Brown and B.J. Enquist, 1997, A general model of the origin of allometric scaling laws in biology, Science 276, 122-26.

West G.B., J. H. Brown and B.J. Enquist, 2001, A general model of ontogenetic growth, Nature 413, 628-31. 


\section{Appendix A: On the Nummerical Analysis of the Model}

Stability. For stability analysis we evaluate the Jacobian determinant of system (12) numerically. Given the value of $b$ fixed by nature, we have identified the elasticities $\alpha$ and $\phi$ and weight on child quantity in utility $\gamma$ as the parameters whose change induces the strongest reaction of dynamic behavior. Figure A shows the eigenvalues of the Jacobian and alternative $\alpha$. White dots on the left hand side demonstrate robustness of our benchmark calibration with parameters from Table 1 . Black dots reflect results for the case of $\phi=1.5$, indicating a strong violation of the physiological check. The system becomes now unstable for $\alpha>0.8$.

Figure A: Eigenvalues
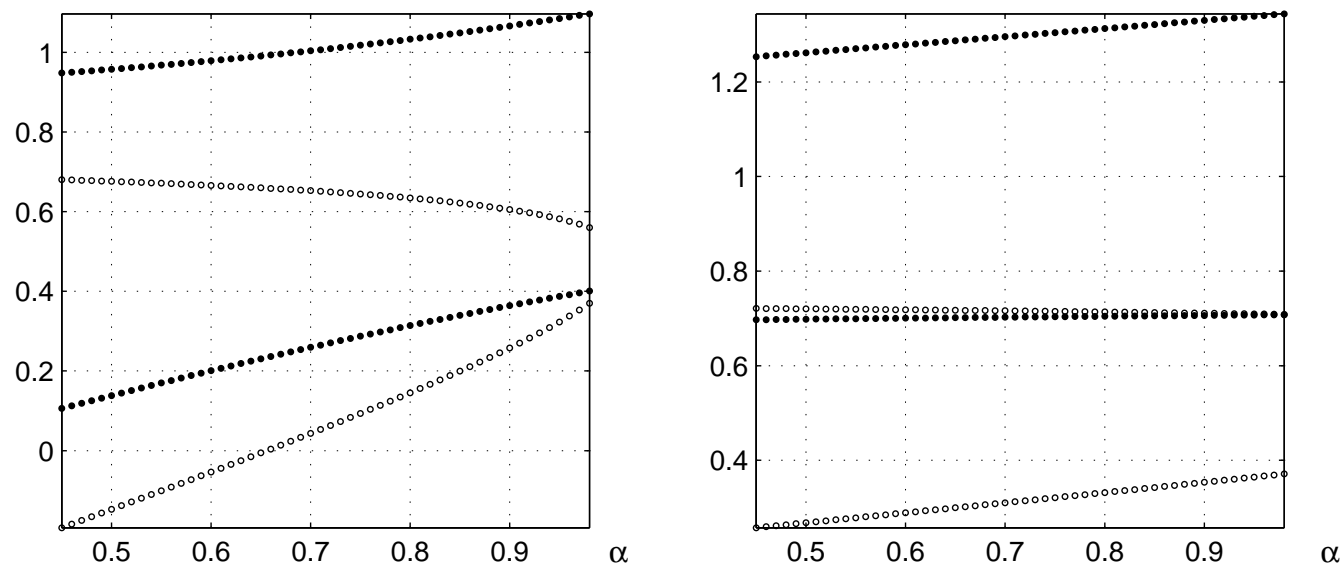

Parameters from Table 1 and alternative values of $\alpha$. Left hand side: white dots: benchmark case from Table 1. black dots: $\phi=1.5$. Right hand side: Lower weight on child quantity $(\gamma=1.52)$ and $\phi=.25$ (white dots) and $\phi=1.5$ (black dots). All other parameters taken from Table 1.

While the region of instability under violation of the physiological check is relatively small for our benchmark scenario, it can be easily become salient in alternative settings. This is in particular the case if $\gamma$ is low, implying that parents' utility depends relatively strongly on child quality. A low value of $\gamma$ introduces a tendency for instability since parents react on improving economic conditions mainly by nourishing their offsprings better. The panel on the right hand side shows the eigenvalues for $\gamma=1.5$. White dots represent a scenario for which all other parameters are taken from Table 1 . In particular, $\phi=0.25$, implying an operative physiological check. Both eigenvalues are smaller than unity over the whole range of $\alpha$ 's, indicating stability. If, on the other hand, $\phi=1.5$, indicating a violation of the physiological check, the system is unstable for all $\alpha>0.5$. In conclusion the positive check (i.e. $\alpha<1$ ) is, generally, not sufficient to stabilize a Malthusian economy. It needs to interact with the physiological check.

An evolutionary argument for the size of $\gamma$. In light of the models' sensitivity to the value of $\gamma$ it is of interest to try to gauge a likely size of this parameter. As it turns out, the weight of child quantity in the utility function can be given an evolutionary motivation, from which a magnitude is implied. 
Suppose nature maximizes genetic fitness, given by the total number of descendants produced. Denote by $\pi_{t}$ the fraction of surviving children. Then genetic fitness of the current generation is given by $\prod_{t=0}^{\infty} \pi_{t} n_{t}$. As the solution of the maximization problem is invariant to a monotonous transformation of the objective function, we let nature maximize the logarithm of genetic fitness so that the objective becomes $\max \sum_{t=0}^{\infty} \log \pi_{t}+\sum_{t=0}^{\infty} \log n_{t}$. From the allometric literature we know that longevity (survival probability) of free living animals scales with body mass at factor $1 / 4$ (e.g., Brown et al., 2004), i.e. $\pi_{t} \propto m_{t}^{\psi}, \psi=1 / 4$. Evaluating (6) at the steady-state, we find that $m_{t} \propto c_{t}$ and thus $\log \pi_{t} \propto \psi \cdot \log c_{t}$. Inserting this information into "nature's objective function" and dividing through by $\psi$, we find that maximizing genetic fitness is tantamount to maximizing $\sum_{t=0}^{\infty}\left[\log \left(c_{t}\right)+(1 / \psi) \cdot \log \left(n_{t}\right)\right]$. This is fulfilled when parents's of each generation maximize $(7)$ for $\beta=0$ and $\gamma=1 / \psi$. Note that evolutionary considerations thus predict $\gamma \approx 4$. This is the value we will use in our calibrations. Note that this relatively high value for $\gamma$ serves to stabilize the economic systems (cf above).

Observe, finally, that this argument precludes that parents derive utility from own consumption, beyond metabolic needs. In a previous version of this research (Dalgaard and Strulik, 2010) we show that all our key results go through if $\beta=0$, i.e. if parents only care about child nutrition and family size, but not about own consumption beyond metabolic needs.

\section{Appendix B: Body Size of the Grown Up Child in the Utility Function}

This section develops a version of the model where parents derive utility from child body size (instead of food expenditure for children). Parents now maximize (18) subject to (6) and (8).

$$
U\left(c_{t}, n_{t}\right)=\beta \log \left(p_{t}\right)+\log \left(m_{t+1}\right)+\gamma \log \left(n_{t}\right)
$$

By contrast to the baseline model, sophisticated parents take the law of motion for body size into account in their maximization of utility i.e. they understand how child nutrition affects ontogenetic growth. Solving the first order conditions for the variables of interest leads to the solution (19) .

$$
\begin{aligned}
p_{t} & =\frac{\beta\left[y_{t}-\left(B_{0} / \epsilon\right) m_{t}^{b}\right]}{\beta+\gamma} \\
c_{t} & =\frac{a \epsilon\left[\tau y_{t}+\rho\left(B_{0} / \epsilon\right) m_{t}^{b}\right]-\gamma(1-d) \mu m_{t}}{(\gamma-1) a \epsilon} \\
n_{t} & =\frac{(\gamma-1)\left[y_{t}-\left(B_{0} / \epsilon\right) m_{t}^{b}\right]}{(\beta+\gamma)\left[a \epsilon\left(\tau y_{t}+\rho\left(B_{0} / \epsilon\right) m_{t}^{b}\right]-(1-d) \mu m_{t}\right.}
\end{aligned}
$$

Inserting nutrition expenditure (19b) into (6) provides the law of motion for body size (20a) and inserting fertility (19c) into (11) provides the law of motion for population size (20b).

$$
\begin{aligned}
m_{t+1} & =\frac{a\left(\tau \epsilon y+\rho B_{0} m_{t}^{b}\right)-(1-d) \mu m_{t}}{\gamma-1} \\
L_{t+1} & =\frac{(\gamma-1) a\left(\epsilon y-B_{0} m_{t}^{b}\right)}{(\gamma+\beta)\left[a(\rho B+\tau \epsilon y)-(1-d) \mu m_{t}\right]} \cdot L_{t},
\end{aligned}
$$


with $y$ determined by (10). At the steady-state, $n_{t}=n^{*}=1$. Using this information in (19c) and solving for $y$ provides (21).

$$
y^{*}=\frac{\gamma+\beta}{a \epsilon} m^{*}+\frac{B_{0}}{\epsilon}\left(m^{*}\right)^{b} .
$$

The utility-from-child-size model thus preserves the positive association of income and body-size. Since $y^{*}$ does not directly depend on $a, d$, or $\rho$, the model preserves the feature of a positive association across steady-states when countries differ (genetically) in stature of their inhabitants. Substituting (21) into (20a) provides body size at the steady-state.

$$
m^{*}=\left[\frac{(\tau+\rho) a B_{0}}{\gamma-1-(\gamma+\beta) \tau+(1-d) \mu}\right]^{1 /(1-b)} .
$$

This expression looks very similar to the original $m^{*}$ from the baseline model. Inserting $y^{*}$ into (20b) provides population density at the steady-state.

$$
\left(\frac{L}{X}\right)^{*}=\left(\frac{a \epsilon A}{(\gamma+\beta)\left(m^{*}\right)^{1-\phi}+a B_{0}\left(m^{*}\right)^{b-\phi}}\right)^{\frac{1}{1-\alpha}} .
$$

Note that population density does not directly depend on $a, d$, or $\rho$. This means that the utility-from-child-size model preserves the feature of a positive association between body size and income across country-specific steady-states when countries differ (genetically) in stature of their inhabitants. The expression (23) is less compact than in the baseline model. But visual inspection reveal that the utility-from-child-size model preserves the features of the baseline model stated in Proposition 2, 3 and in Corollary 1.

\section{Appendix C: Data Sources}

Countries represented in our data set: Bangladesh, Benin, Burkina Faso , Cambodia, Cameroon, Central African Republic ; Chad ; Comoros; Congo, Dem. Rep.; Congo, Rep; Cote d'Ivoire ;Eritrea; Ethiopia; Gabon; Ghana ; Guatemala ; Guinea; Haiti; Honduras; Kenya; Lesotho; Liberia; Madagascar ; Malawi; Mali; Mauritania; Mozambique; Namibia; Nepal; Nicaragua; Niger; Nigeria; Rwanda; Senegal; Sierra Leone; Togo; Uganda; Zambia.

Sample. As noted in the text we employ only countries for which (a) data is available for body size, and, (b) that Reher (2004) classifies as "latecommers" to the demographic transition. "Latecommers" are those where the fertility transition occurred in 1980 or later. Reher (2004, p. 21) explains the criteria for pinpointing the date of the transition:" It has been set at the beginning of the first quinquennium after a peak, where fertility declines by at least $8 \%$ over two quinquennia and never increases again to levels approximating the original takeoff point".

Weight and height (female) Source: From Demographic and Health Survey ("Stat compiler"). Data is available online via: http://www.statcompiler.com/. We pick surveys around the year 2000, as noted in the text. In some cases two surveys are equally "close" to 2000. For instance, one in 1997 and one in 2003 (e.g., Madagascar, Mozambique). In these cases we choose the earliest available survey.Data on weight is not directly available; but height and BMI are. Hence, since BMI is defined as height (in meters) divided by the square root of weight (in $\mathrm{kg}$ ), we can back out weight.

Population density in 2000. Source: World Development Indicators. 
GDP per worker in 2000 (PPP). Source: Penn World Table 6.3.

GDP per worker, agriculture, in 2000. source: World Development Indicators.

Soil quality. Definition (Nunn and Puga, 2010, p. 8): "Soil that is not subject to severe constraints for growing rainfed crops in terms of either soil fertility, depth, chemical and drainage properties, or moisture storage capacity, and is based on the FAO/UNESCO Digital Soil Map of the World". Source: Nunn and Puga (2010).

Distance to coast. Average distance to ice-free coast. Source: Nunn and Puga (2010).

Near coast. \% area within $100 \mathrm{~km}$ of ice-free coast. Source: Nunn and Puga (2010).

Latitude. Source: Nunn and Puga (2010).

Island dummy. Takes on the value 1 if the country is an Island. Source: CIA Factbook.

Former Colony: British and French. Source: Nunn and Puga (2010).

Ethno-linguistic fractionalization, 1985. Source: Treisman (2007)

Years since the Neolithic, migration weighted. Source: Putterman (2008) and Putterman and Weil (2010).

Terrrain ruggedness. Source: Nunn and Puga (2010).

Tropical. tropical climate zone. Source: Nunn and Puga (2010) 


\section{Appendix D: Robustness CHECKS AND ADDED VARIABles Plots}

Figure A 1: Soil Quality and population density

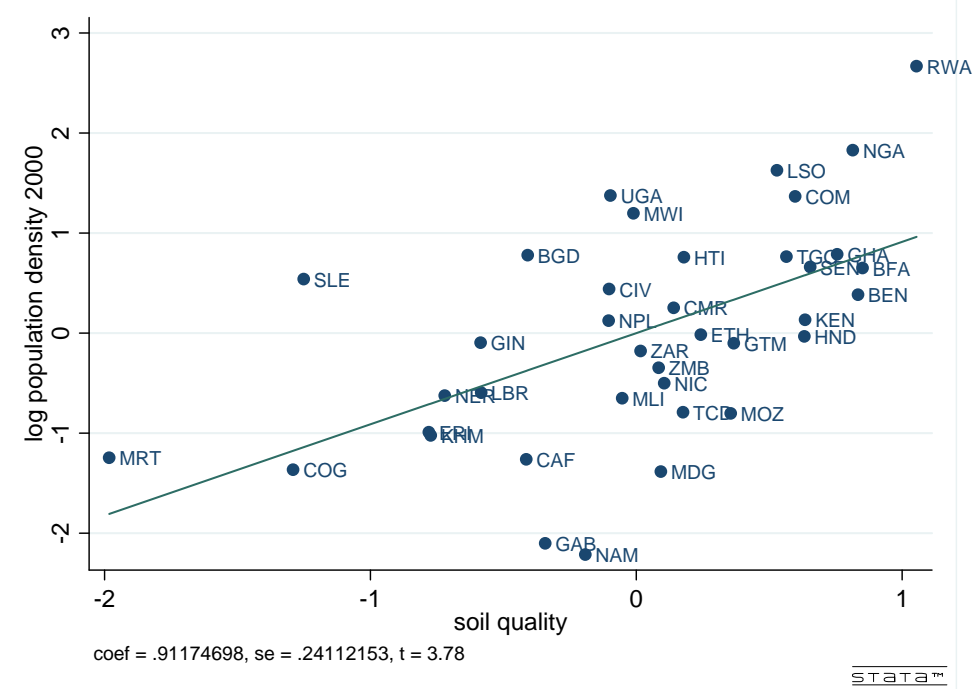

Notes: The figure shows the partial effect of soil quality on population density, while controlling for average body size, absolute latitude, access to waterways and an Africa dummy. Thus, the $\mathrm{x}$ - and y-axes plot the residuals obtained from regressing soil quality on the aforementioned set of covariates. Data sources: See Appendix C.

\section{Figure A 2: Soil Quality and GDP per Worker}

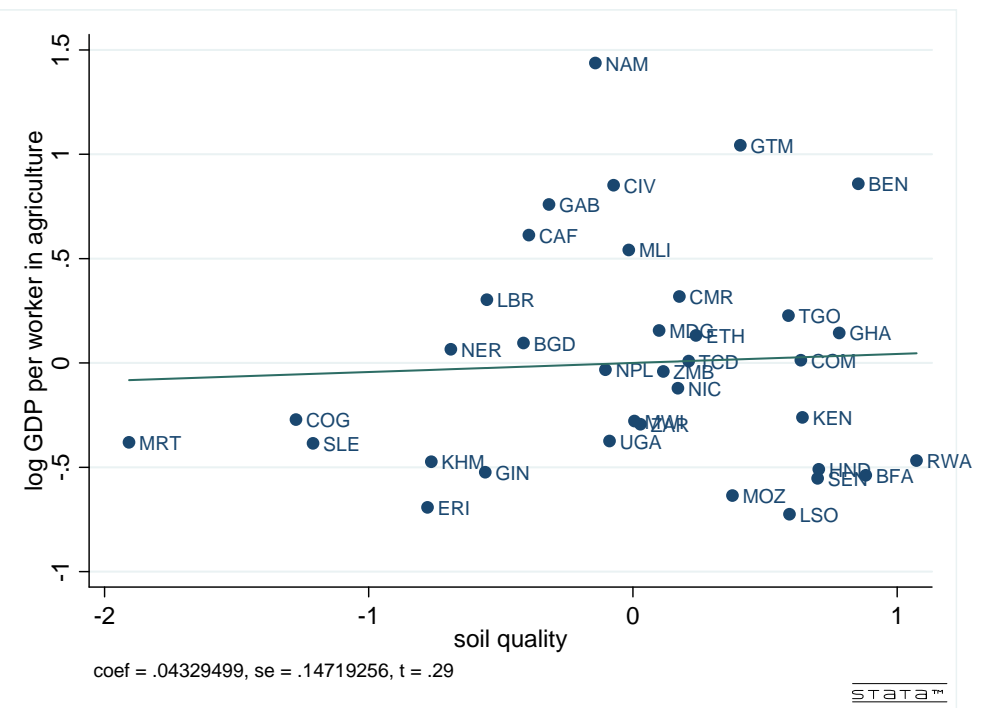

Notes: The figure shows the partial effect of soil quality on GDP per worker in agriculture, while controlling for average body size, absolute latitude, access to waterways and an Africa dummy. Thus, the $\mathrm{x}$ - and y-axes plot the residuals obtained from regressing soil quality on the aforementioned set of covariates. Data sources: See Appendix C. 
Figure A 3: The physiological check

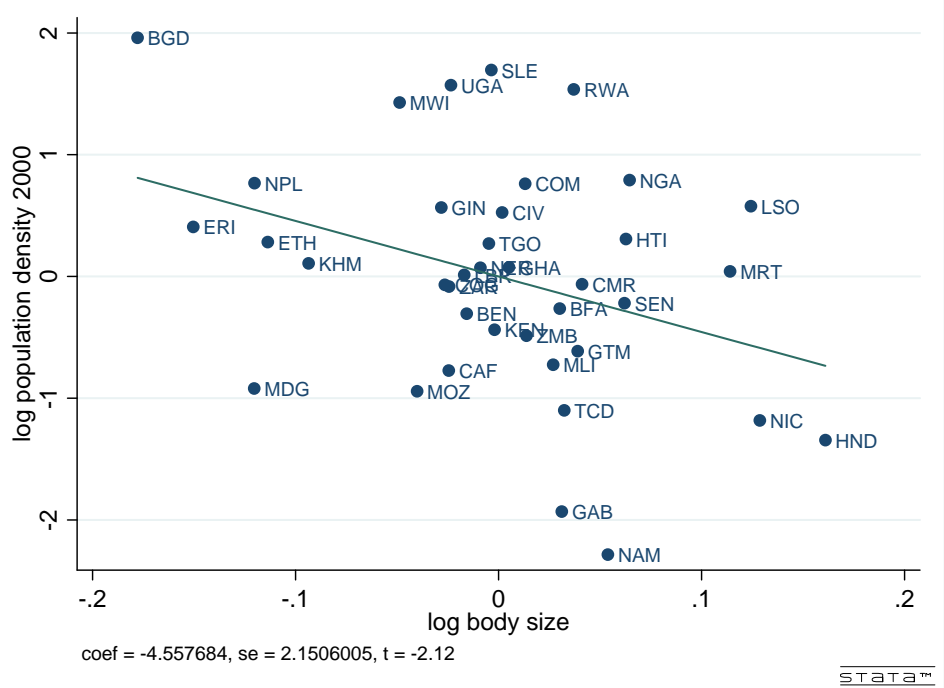

Notes: The figure shows the partial effect of body size on population density, while controlling for soil quality, absolute latitude, access to waterways and an Africa dummy. Thus, the $\mathrm{x}$ - and $\mathrm{y}$-axes plot the residuals obtained from regressing body size on the aforementioned set of covariates. Data sources: See Appendix C.

Figure A 4: Body size and productivity

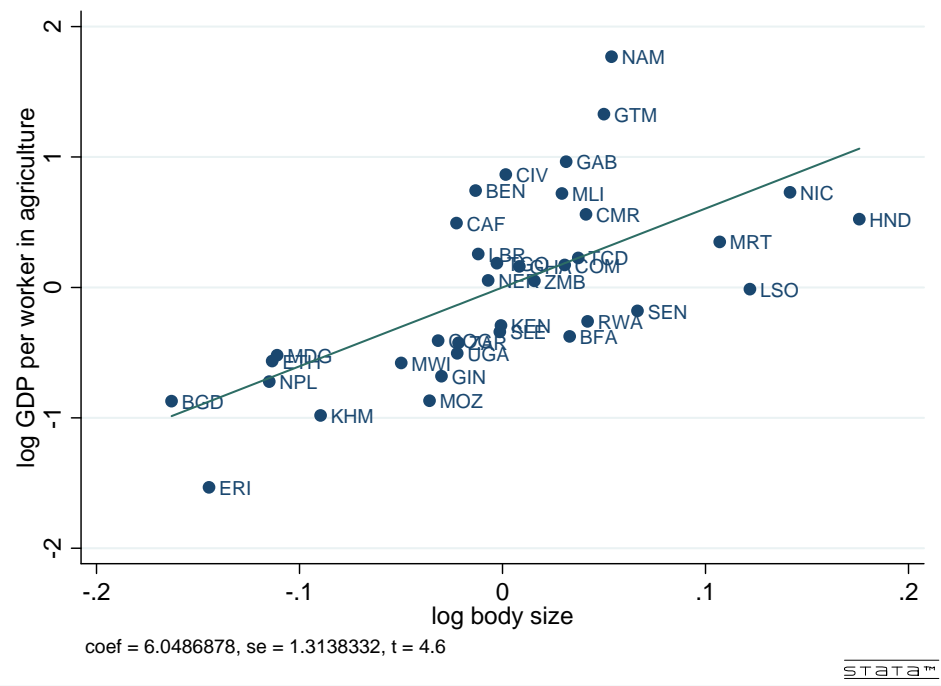

Notes: The figure shows the partial effect of body size on GDP per worker in agriculture, while controlling for soil quality, absolute latitude, access to waterways and an Africa dummy. Thus, the $\mathrm{x}$ - and y-axes plot the residuals obtained from regressing body size on the aforementioned set of covariates. Data sources: See Appendix C. 


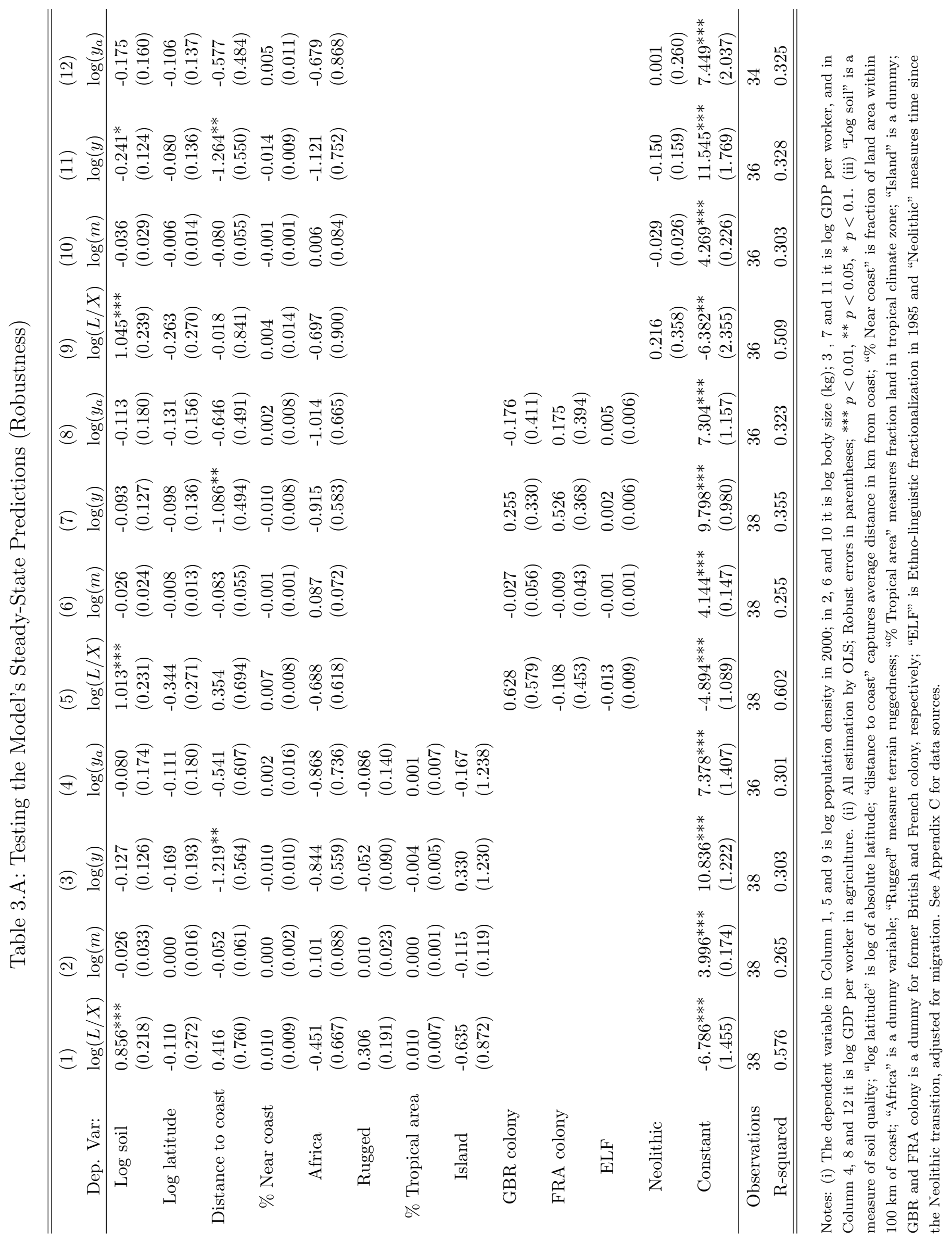




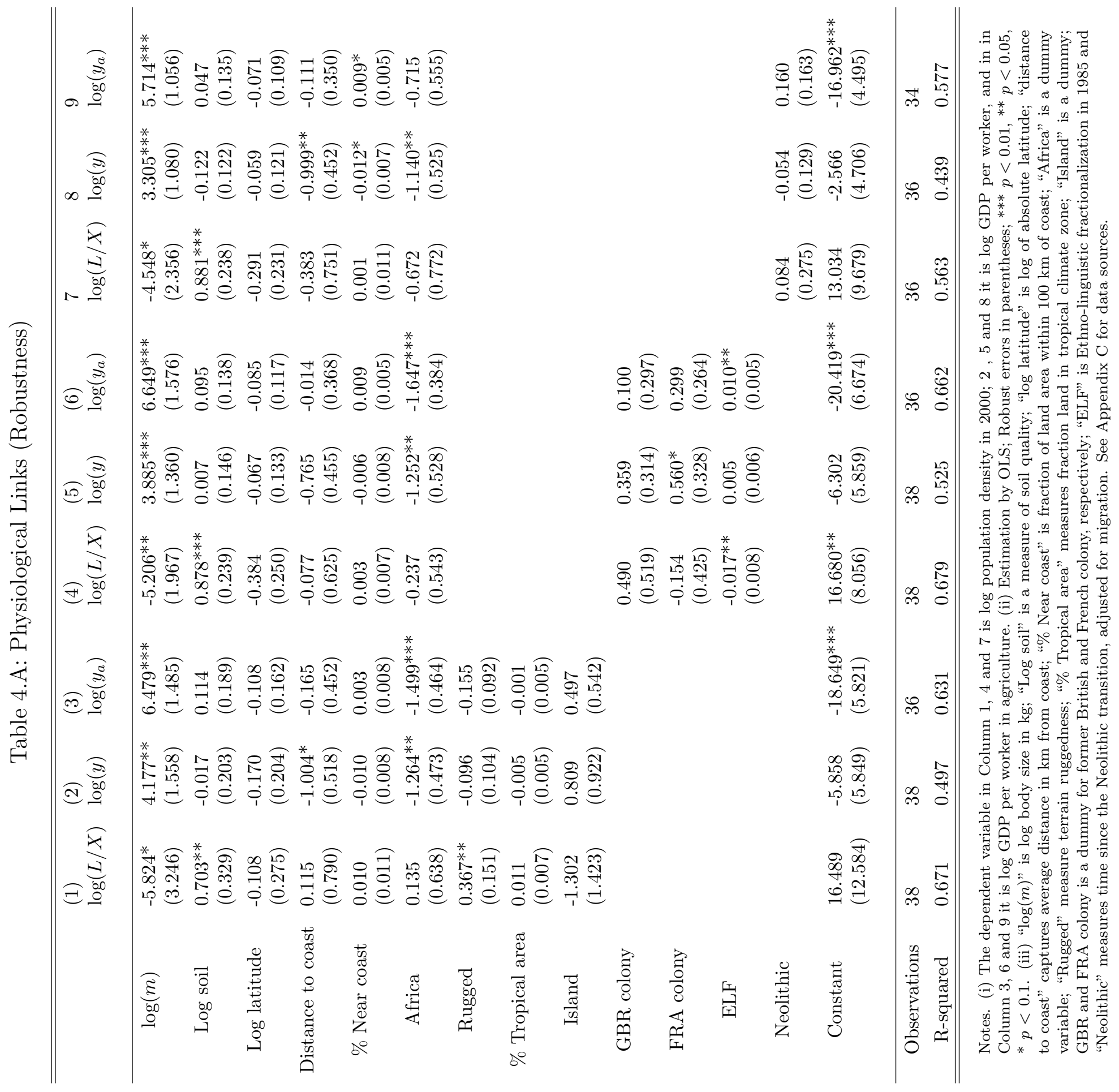

